\title{
Probabilistic residual ultimate strength assessment of cracked unstiffened and stiffened plates under uniaxial compression
}

\author{
Wentao He ${ }^{\mathrm{a}, \mathrm{b}}$, Xiaofei Cui ${ }^{\mathrm{a}}$, Zhiqiang $\mathrm{Hu}^{\mathrm{c}}$, Jingxi Liu ${ }^{\mathrm{d}}$, Changzi Wang ${ }^{\mathrm{a}}{ }^{*}$, Lu Yao ${ }^{\mathrm{a}^{*}}$ \\ ${ }^{a}$ College of Engineering, Ocean University of China, Qingdao 266100, China \\ ${ }^{\mathrm{b}}$ Shandong Provincial Key Laboratory of Ocean Engineering, Ocean University of \\ China, Qingdao 266100, China
}

${ }^{c}$ School of Engineering, Newcastle University, Newcastle upon Tyne, NE1 7RU, UK

${ }^{\mathrm{d}}$ School of Naval Architecture and Ocean Engineering, Huazhong University of Science and Technology, Wuhan, Hubei 430074, China

*Corresponding Author

E-mail: polywcz@163.com

Tel.: 86-532-66781550

Fax: 86-532-66781550 


\begin{abstract}
This paper proposes a reliable approach to evaluate the probabilistic residual ultimate strength of cracked unstiffened/stiffened plates by coupling nonlinear finite element analysis and Kriging-based reliability method. A numerical simulation scheme is established to evaluate the residual ultimate strength of cracked plates under uniaxial compression loading, considering the influence of uncertain initial imperfections, cracking damages and material parameters. To improve the efficiency of assessment, Kriging-based Monte Carlo simulation method combined with an active learning (AK-MCS) strategy is adopted to achieve the reliability analysis of ultimate strength. Firstly, a deterministic analysis is implemented to explore the influence of basic variables on the ultimate strength reduction characteristics of cracked plates. Then, probabilistic reliability analysis is performed to investigate the evolution of failure probability and reliability index of each uncertain parameter and to evaluate reliability index of design objective for ultimate strength. Sensitivity analysis of uncertain parameters on the reliability index and failure probability is studied, and the result reveals that its variation tendency is consistent with deterministic analysis. The reliability index is achieved by AK-MCS with a few of FEM calls, indicating the proposed probabilistic ultimate strength assessment method is accurate and efficient for structural reliability analysis of cracked plates.
\end{abstract}

Keywords: Ultimate strength; Cracked plate; Kriging model; Initial imperfection; Reliability index. 


\section{Introduction}

Ships and offshore structures are inevitable to suffer from different kinds of initial imperfections and cracking damages during their manufacture and service life (Saad-Eldeen et al., 2018; Cui et al., 2016; Xu et al., 2014). Crack is one of the most common damage in aged marine structures, which may be initiated at structural discontinuity, welded joints and stress concentration regions (He et al., 2014, 2020). It is common sense that cracks could significantly worsen the buckling performance, consequently reduce the load bearing capacity of structures, possibly causing a catastrophic collapse of the whole structure (Wang et al., 2015; Gao et al., 2012; Xia et al., 2019). Therefore, it is crucial to predict the ultimate strength of hull structures based on deterministic methods when they come across extraordinary terrible loading conditions. However, there is a large degree of uncertainty for crack initiation and propagation, leading to various sizes, locations and orientations of cracks. So it is vitally important to thoroughly explore probabilistic ultimate strength assessment under compressive loading during the damage-tolerant design and service period ( $\mathrm{Xu}$ et al., 2015; Cui et al., 2012; Amlashi and Moan, 2019; Benson et al., 2013).

Ships and offshore structures are basically assembled from unstiffened and stiffened plate components, and the overall strength of structures is determined by the ultimate strength of a single component. Therefore, ultimate strength assessment of unstiffened and stiffened plates is a primary task to guarantee the economic design and structural safety. Traditionally, the structure design and mechanical analysis depend largely on deterministic methods. With this regard, a considerable amount of research has been performed on the residual ultimate strength of cracked unstiffened and stiffened plates under longitudinal compression based on deterministic methods. The main influence variables for ultimate strength in these References (Table 1) are initial distortions, crack 
size, crack orientation and crack location, which have different levels of effect on residual ultimate strength of cracked plates.

Corresponding to the damage-tolerant design, risk-based inspection (RBI) planning has been proposed and explored to evaluate the optimal inspection and maintenance strategies of aged structures in a decision-making process. In the RBI process, structural reliability analysis as a key component is employed to identify the primary factors among basic random variables (structural configuration, material characteristics, local and global imperfections and so on) affecting the structural safety and integrity (He et al., 2015). Recently, reliability-based approaches have received more and more attention in the ship structural design, aiming to reasonably quantify the uncertainties in design variables via probabilistic models. Probabilistic modelling of ultimate strength for unstiffened and stiffened plates basically involves two aspects: the ultimate strength assessment of cracked plate, and the structural reliability analysis considering random variables. From the above literature review, the ultimate strength assessment of unstiffened and stiffened plates normally relates to nonlinear structural behavior, which typically relies on numerical approaches such as nonlinear finite element analysis.

In practice, the conventional approaches for reliability assessment of engineering structures are first-order reliability method (FORM), second-order reliability method (SORM), Monte Carlo simulation (MCS) method and response surface method (RSM). Elhanafi et al. (2017) carried out time-variant reliability analyses of novel Y-stiffener by using SORM. Based on this method, the Y-stiffener profiles had been improved to obtain larger safety index. Yang et al. (2013) proposed a stochastic method to design the tophat stiffened composite plates under compressive loading, associated with Navier grillage theory and FORM. They found that component thickness and fiber content had significant influence on the structural reliability. Omidali and Khedmati (2018) employed the stochastic approach to design the stiffened plates by using First Order Second 
Moment, First Order Reliability Method and Importance Sampling method. The results showed that reliability analysis was immensely sensitive to the parametric statistics of primary design variables. However, for structural reliability analysis with implicit limit state function, Monte Carlo simulation method and response surface method are the most versatile solution methods presently available. Silva et al. (2013) carried out thousands of nonlinear finite element analyses to study the ultimate strength of corroded plates with spatially varying thickness using Monte Carlo simulation method. The results showed that the ultimate strength assessment using Monte Carlo simulation could provide the basic structural design and safety assessment for thin-walled steel plates. Wang et al. (2018) preformed the probabilistic ultimate strength assessment of corroded unstiffened and stiffened plates through a large number of FEA calling, considering varying pitting shape, depth and distribution. Stochastic simulations exhibited that the compressive ultimate strength of plate with random pitting had a lower value than that of a regular one. From the above-mentioned research, it can be seen that the reliability analysis of a practical structure requires a high number of calls of numerical models, e.g. nonlinear finite element analysis (FEA) structural models, for current RSM and MCS approaches. Consequently, it is in general too time consuming and computationally expensive to run so many FEA structural models. In other words, it is very challenging to achieve the reliability analysis involving computationally demanding numerical models for traditional methods, so it is not suitable for design of engineering structures.

In order to solve this problem effectively, surrogate model-based approaches such as polynomial response surfaces (Faravelli, 1989), artificial neural network (ANN) (Papadrakakis et al., 1996), support vector machine (SVM) (Vapnik, 1982) and Kriging model (Vapnik, 1982), have been established as an efficient technique to provide accurate estimates of reliability analysis with lower computational effort. Cui et al. (2019) carried out the probabilistic ultimate strength analysis of a typical bottom stiffened panel with 
localized pitting corrosion by surrogate models and Gaussian process (GP). In GP method, the new design point was added and the constructed surrogate models showed good accuracy and efficiency. Cerik et al. (2013) investigated the probabilistic characteristics of structural ultimate strength for the effects of random geometrical and material properties on failure of submarine pressure hulls, and then sensitivity factors were studied to identify the crucial variables. Seyffert et al. (2019) studied the failure probability of stiffened plates by using nonlinear Design Loads Generator (NL-DLG) process. The results showed that NL-DLG process could quickly and efficiently assess the failure probability of stiffened plates. Gaspar et al. (2012) carried out the structural reliability assessment of hull girder stiffened panels under uniaxial compression and lateral pressure loads by the combination of Monte Carlo simulation and response surface method. The failure probability and reliability index were estimated to study the effect of corrosion on the stiffened panel. From the above literature review, it is noted that the studies on reliability assessment of ultimate strength under compressive loading mainly concentrate on the unstiffened and stiffened plates involving the basic uncertain variables such as initial deformation and corrosion damage, while very limited results have been reported in terms of the probabilistic ultimate strength of cracked unstiffened and stiffened plates.

This paper proposes a reliable approach to evaluate the probabilistic residual ultimate strength of cracked unstiffened/stiffened plates by coupling nonlinear finite element analysis and Kriging-based reliability method. Firstly, a numerical simulation scheme is established to evaluate ultimate strength of cracked plates under uniaxial compression loading, considering the influence of uncertain initial imperfections and cracking damages. To improve efficiency of the assessment, Kriging-based Monte Carlo simulation method combined with active learning strategy is adopted to solve the reliability problem of ultimate strength. Then, a deterministic analysis is implemented to 
explore the influence of uncertain initial deflection, cracking damages and material parameters on the ultimate strength reduction characteristics of cracked plates under uniaxial compression loading. Subsequently, probabilistic reliability analysis is performed to investigate the evolution of failure probability and reliability index of each uncertain parameter and to evaluate reliability index of design objective for ultimate strength. Finally, sensitivity analysis of each potential parameter is investigated for the effect on the failure probability and reliability index.

\section{Description of Finite element analysis}

\subsection{Geometric and material properties}

According to the composition of ship hull structures, two typical structural elements, i.e. unstiffened and stiffened plates, are taken into consideration in this study as one-bay/one-span model, as exhibited in Fig. 1. The geometrical dimensions of elementary plates are determined according to the report of Ultimate Strength Committee of ISSC (ISSC Committee III.1, 2012), whose detail dimensions are listed in Table 2. The dimensions of unstiffened elementary plate are $a=2550 \mathrm{~mm}$ in length, $b=850 \mathrm{~mm}$ in breadth, and $t_{\mathrm{p}}=13 \mathrm{~mm}$ in thickness. The stiffened elementary plate is composed of the same plate and a stiffener with flat-bar profile $200 \mathrm{~mm}$ in height and $15 \mathrm{~mm}$ in thickness. The plate and stiffener are made of AH36 grade, which are considered as an elastic-perfectly plastic material without strain hardening. The material properties yield stress $\sigma_{\mathrm{y}}=393.4 \mathrm{MPa}$, Young's modulus $E=209220 \mathrm{MPa}$ and Poisson's ratio $v=0.3$, which is taken from reference (Kharghani et al., 2019).

The damages in aged steel-structures include corrosion due to the corrosive environment, fatigue cracks due to the random loadings, and local dents due to collision or falling objects. Therefore, initial defects or cracks are most likely to form around the joints between stiffeners and plates as well as the local regions of corrosion pits or dents. In practice, the crack emerging in the unstiffened or stiffened elementary plates is 
basically random, including crack length, crack orientation and crack location. The crack length is described as $l$, and the crack orientation $\theta$ is defined as the angle between the crack and longitudinal compression direction. The longitudinal distance $h$ and transverse distance $v$ are distances from the crack center to the short free edge and long free edge of the plate, respectively. For stiffened plate, the height of stiffener is $s$, and there is a crack of length $c$ perpendicular to intersecting line of the stiffener and plate. It should be noted that the crack propagation is not considered in this paper. A more common approach is that a semi-circle with a diameter of $3 \mathrm{~mm}$ at each crack-tip is adopted to prevent crack propagation according to the Reference (Xu et al., 2014). The hypothesis is reasonable for cracked plate with semi-circle crack-tip and high ductility material subjected to monotonically increasing compressive loading (Xu et al., 2014; Paik et al., 2005). In general, the plate reaches its ultimate strength before the crack faces coming into contact for the gap size more than $3 \mathrm{~mm}$ (Paik et al. 2005). The effect of contact for crack surface on the ultimate strength of cracked plate has been investigated under uniaxial compression (Margaritis et al., 2012; Cui et al., 2017). The result indicates that the axial compression distance of cracked plate is relatively small until the ultimate strength is achieved, and consequently crack surfaces may not come into contact if the crack gap is more than $3 \mathrm{~mm}$. Therefore, the contact of crack surface is not taken account for a conservative prediction on the ultimate compressive strength characteristics of cracked plate in this study.

\subsection{Boundary and loading conditions}

Cracked unstiffened and stiffened elementary plates are extracted from continuous plated structures such as ship hull girders. Therefore, the boundary and loading conditions of elementary plates are dependent on the support members connected to target structures. The detailed boundary and loading conditions of cracked elementary plates are illustrated in Fig. 2. For the unstiffened plate, the four free edges are assumed 
to be simply supported and kept straight to model practical behavior as accurately as possible. For the stiffened plate, symmetric boundaries are employed to two long edges parallel to the stiffener, whereas simply supported boundary condition is applied to the other edges of the plate and stiffener. Uniform displacement along $\mathrm{x}$ axis is exerted on the simply supported end at $\mathrm{x}=0$ to apply longitudinal compressive action.

\subsection{Initial imperfection}

It is inevitable to produce initial imperfections for elementary plates of ship structures due to the complex fabrication process of flame cutting and fusion welding. The initial imperfections of unstiffened and stiffened plates could reduce the structural stiffness and ultimate strength in certain degree. Therefore, the buckling/collapse behaviors of elementary plates under uniaxial compression are closely dependent on the magnitude and spatial variation of initial deformations. For welded steel plates, the initial deflections can be classified into three categories: plating, column-type and side-ways initial deflections. The initial deflection considered in this study is the combination of three types of buckling mode shapes for stiffened plates.

Initial deflection of local plate between stiffeners,

$$
w_{o p l}=A_{0} \sin \frac{m \pi x}{a} \sin \frac{\pi y}{b}+B_{0} \sin \frac{\pi x}{a}
$$

Column-type initial deflection of stiffener,

$$
w_{o c}=B_{0} \sin \frac{\pi x}{a}
$$

Side-ways initial deflection of stiffener,

$$
w_{o s}=C_{0} \frac{z}{h_{w}} \sin \frac{\pi x}{a}
$$

where $a$ and $b$ are the length and width of elementary plate, and $A_{0}=\alpha \beta^{2} t$, $B_{0}=C_{0}=0.0015 a$ are the amplitudes of three types of initial deflection shapes. $\beta$ is 
the slenderness ratio of the plate and defined by $\beta=b / t \sqrt{\sigma_{y} / E}, \alpha$ is the initial deflection amplitude coefficient. $m$ is the buckling half wave number in the plate length direction, which is equal to $a / b$. If $a / b$ is not an integer, $m$ is considered to be the minimum integer meeting the following condition,

$$
a / b \leq \sqrt{m(m+1)}
$$

According to the measured deformation data of ship structures, maximum initial deflections can be divided into three levels, "slight", "average" and "severe", which are relevant to welding quality. In practical applications, the average-level magnitude of initial imperfection is commonly adopted within the up-to-date technological level of shipping and marine industries (Paik, 2008).

In order to implement probabilistic residual ultimate strength assessment in the finite element analysis, the initial imperfection is introduced automatically by adjusting the coordinate positions in the framework of Python program. Fig. 3 illustrates two typical examples of applied initial deflection shapes (with magnification of $10 \times$ ) for the unstiffened and stiffened plates prior to application of longitudinal compression loading.

\subsection{Adopted element type and convergence study}

The ultimate strength assessment of structure is a nonlinear analysis owing to both geometric and material nonlinearities. The Newton-Raphson (NR) method built-in ABAQUS is applied to assess the buckling/plastic collapse behaviors of unstiffened/stiffened plates under longitudinal compression loading. For the FE model, cracked plates are discretized as shell elements S4R (4-node, quadrilateral, stress/displacement shell element with reduced integration), which is well-suited for elastic-plastic large deflection analysis of thin-walled structures.

The meshes at crack-tip should be fine enough to obtain the accurate and reliable assessment of ultimate strength for cracked unstiffened/stiffened plates. Therefore, a 
rectangular partition outside the crack is created for the convenience of meshing using Python programming, where the finer mesh is set by the advancing front-refined meshing algorithm. The mesh generation around the crack-tip is described in Fig. 4. To achieve a balance between accuracy and computational time, a convergence study with varying mesh size should be carried out, and the obtained residual ultimate strength with different mesh size is listed in Table 3. As it can be seen, there is no evident distinction among the obtained values of ultimate strength when the mesh size is less than $50 \mathrm{~mm}$ in the region outside the crack, so mesh size of $30 \mathrm{~mm}$ has been chosen for mesh generation in all cases.

\section{Kriging-based Monte Carlo simulation method for ultimate strength}

It is quite challenging to assess the probabilistic residual strength since it needs excessively computational effort to run so much finite element analysis (FEA). To address this drawback, Kriging-based Monte Carlo simulation method combined with an active learning is adopted to reduce the total number of calls to FEA.

\subsection{Kriging model}

More recently, Kriging model is widely applied to approximate the performance function as an adaptive surrogate model for structural reliability analysis of engineering structure (Echard et al., 2011). In essence, the approximated performance function $G(\boldsymbol{x})$ can be considered as a realization of statistical Gaussian process, which is composed of linear regression model $F(\boldsymbol{x}) \boldsymbol{\beta}$ and nonparametric stochastic error $Z(\boldsymbol{x})$ (Lophaven et al., 2002; Kaymaz, 2005). So the limit state function is written as,

$$
G(\boldsymbol{x})=F(\boldsymbol{x}) \boldsymbol{\beta}+Z(\boldsymbol{x})
$$


where $F(\boldsymbol{x})$ is the basic function obtained by regression analysis, $\boldsymbol{\beta}$ is the vector of regression coefficients, and $Z(\boldsymbol{x})$ is the realization of a stochastic process with zero-mean. The covariance between $Z(\boldsymbol{x})$ and $Z(\boldsymbol{w})$ is defined by,

$$
\operatorname{Cov}[Z(\boldsymbol{x}), Z(\boldsymbol{w})]=\sigma_{Z}^{2} \mathfrak{R}(\boldsymbol{\theta}, \boldsymbol{x}, \boldsymbol{w})
$$

where $\sigma_{Z}^{2}$ is the process variance and $\mathfrak{R}$ is the spatial correlation function with its set of parameters $\boldsymbol{\theta}$ to control the smoothness of Kriging model. Correlation function has some effects on the weight of adjacent points during prediction. Generally, Gaussian correlation function performs better for the evaluation of nonlinear performance function, whereas exponential and linear functions are well suited for approximately linear problems. The most commonly used correlation function for reliability analysis in engineering structures is Gaussian function (Echard et al., 2011; Kaymaz, 2005), which is expressed by,

$$
\mathfrak{R}(\boldsymbol{\theta}, \boldsymbol{x}, \boldsymbol{w})=\prod_{i=1}^{n} \exp \left[-\theta_{i}\left(x_{i}-w_{i}\right)^{2}\right]
$$

where $n$ is the number of design variables, $\theta_{i}$ is the correlation parameter in the $i^{t h}$ dimension, $x_{i}$ and $w_{i}$ are the $i^{t h}$ components of input points.

Given a design of experiment with $m$ sampling points $\left\lfloor\boldsymbol{x}^{(1)}, \ldots, \boldsymbol{x}^{(m)}\right\rfloor$ with $\boldsymbol{x}^{(i)} \in \boldsymbol{R}^{n}$, the limit state function values $\boldsymbol{y}$ with $\boldsymbol{y}^{(i)}=G\left(\boldsymbol{x}^{(i)}\right) \in \boldsymbol{R}$ can be calculated by running $G(\boldsymbol{x})$ for each sampling point. So the scalars $\boldsymbol{\beta}$ and $\sigma_{z}^{2}$ can be estimated by,

$$
\begin{gathered}
\hat{\boldsymbol{\beta}}=\left(\mathbf{F}^{T} \mathbf{R}^{-1} \mathbf{F}\right)^{-1} \mathbf{F}^{T} \mathbf{R}^{-1} \mathbf{y} \\
\hat{\sigma}_{Z}^{2}=\frac{1}{m}(\boldsymbol{y}-\boldsymbol{F} \hat{\boldsymbol{\beta}})^{T} \boldsymbol{R}^{-1}(\boldsymbol{y}-\boldsymbol{F} \hat{\boldsymbol{\beta}})
\end{gathered}
$$


where $\boldsymbol{F}$ and $\boldsymbol{R}$ represent the regression and correlation matrixes, respectively. The correlation parameters $\boldsymbol{\theta}$ have a significant effect on Kriging model, so the parameters $\boldsymbol{\theta}$ can be calculated through the method of maximum likelihood estimation procedure,

$$
\hat{\boldsymbol{\theta}}=\arg \min _{\boldsymbol{\theta}}\left\{|\boldsymbol{R}(\boldsymbol{\theta})|^{1 / m} \hat{\sigma}_{Z}^{2}(\boldsymbol{\theta})\right\}
$$

The Best Linear Unbiased Predictor $\hat{G}(\mathbf{x})$ of a specified point in the random variables can be computed by,

$$
\hat{G}(\boldsymbol{x})=f(\boldsymbol{x})^{T} \hat{\boldsymbol{\beta}}+r(\boldsymbol{x})^{T} \boldsymbol{R}^{-1}(\boldsymbol{y}-\boldsymbol{F} \hat{\beta})
$$

where, $\quad r(\boldsymbol{x})^{T}=\left\lfloor\mathfrak{R}\left(\hat{\boldsymbol{\theta}} ; \boldsymbol{x}, \boldsymbol{w}^{(1)}\right), \cdots, \mathfrak{R}\left(\hat{\boldsymbol{\theta}} ; \boldsymbol{x}, \boldsymbol{w}^{(m)}\right)\right\rfloor$.

The Kriging predictor variance $\hat{\sigma}_{\hat{G}}^{2}(\boldsymbol{x})$ is evaluated by the minimum of mean squared error between $\hat{G}(\boldsymbol{x})$ and $G(x)$, which is defined by,

$$
\hat{\sigma}_{\hat{G}}^{2}(\boldsymbol{x})=\hat{\sigma}_{Z}^{2}\left\lfloor 1+\boldsymbol{u}(\boldsymbol{x})^{T}\left(\boldsymbol{F}^{T} \boldsymbol{R}^{-1} \boldsymbol{F}\right)^{-1} \boldsymbol{u}(\boldsymbol{x})-\boldsymbol{r}(\boldsymbol{x})^{T} \boldsymbol{R}^{-1} \boldsymbol{r}(\boldsymbol{x})\right\rfloor
$$

where, $\boldsymbol{u}(\boldsymbol{x})=\boldsymbol{F}^{T} \boldsymbol{R}^{-1} r(x)-f(x)$.

The correlation function parameter $\theta$ is very important for constructing Kriging surrogate model, and the initial value $\theta$ significantly affects the construction of model (Kaymaz, 2005), especially for probability analysis. On the other hand, a pattern search method is employed to determine $\hat{\theta}$, while it is more prone to be trapped in local minima (Luo et al., 2012). For this case, the global search method is considered as a highly efficient solution, so the genetic algorithm (GA) is adopted to optimize $\theta$ in this study.

\subsection{Assessment of structural reliability}

It is common sense that ships and offshore structures are inevitable to suffer from different kinds of initial imperfections and cracking damages due to corrosion, welding, collision, cyclic loading and so on. Substantially, there is a considerable degree of uncertainty for initial imperfections, cracking damages and material parameters, which 
reflect the main statistical characteristics of unstiffened/stiffened plates. Therefore, the crack length, crack orientation, crack locations, initial deflection and yield stress are considered as the main random variables for probabilistic residual ultimate strength assessment of cracked unstiffened and stiffened plates.

For the structural reliability assessment, it is necessary to formulate the limit-state function to distinguish the safety and failure domains. With respect to the probabilistic residual ultimate strength assessment, the implicit limit-state function can be defined according to the resisting strength and the applied compressive load (Elhanafi et al., 2017; Yang et al., 2013; Chen et al., 2007; He et al., 2013),

$$
G(X)=\sigma_{u}^{\text {resiłant }}(X)-\sigma_{u}^{\text {applied }}
$$

where $X=\left(x_{1}, x_{2}, \cdots, x_{n}\right)$ is a $n$-dimensional random vector representing the uncertain parameters in the model. $\sigma_{u}^{\text {resisant }}(X)$ is the resisting ultimate strength of cracked plate corresponding to structural failure; $\sigma_{u}^{\text {applied }}$ represents the applied compressive load on the stiffened plate of ship deck, which can be calculated from the total vertical bending moment and the mid-ship section modulus. Here, for the sake of simplification, $\sigma_{u}^{\text {applied }}$ is designed as $R \sigma_{u}^{0} . \sigma_{u}^{0}$ is determined by ultimate strength of intact plate with initial distortion of average level $(\alpha=0.1)$ according to the manufacturing technology of welded-metal plate structures within the maritime industry. $R$ is the ultimate strength loss factor.

The failure probability $P_{f}$ is written as,

$$
P_{f}=\operatorname{prob}(\hat{G}(\boldsymbol{x}) \leq 0)
$$

And the corresponding reliability index $\beta$ can be expressed by the inverse standard normal cumulative distribution function operator $\left(\Phi^{-1}\right)$, 


$$
\beta=-\Phi^{-1}\left(P_{f}\right)
$$

\subsection{Numerical implementation}

The main implementation process of Kriging-based Monte Carlo simulation method follows the framework depicted in Fig. 5, which can be summarized as the following steps:

1) Generate a Monte-Carlo population as the candidate sample set $S=\left\{\mathbf{X}^{(i)}, i=1, \cdots, n_{M C}\right\}$. About $10^{5} \sim 10^{6}$ candidate points are generated according to joint probability density function by Monte-Carlo simulation. These candidate points need to be evaluated on the performance function if the active learning scheme requires it in step 7 .

2) Define the initial design of experiment (DoE) points. To perform Kriging, a rather small set of DoE points is required as an initial training sample set to construct the initial Kriging model. DoE points of size $N_{\text {call }}$ are generated by Hammersley sampling. According to our experience, $N_{\text {call }}$ is selected by the number of uncertain variables $(n), N_{\text {call }}=k n, k=3 \sim 5$.

3) Evaluate the ultimate compressive strength by FEA. The selected initial DoE points as input structural parameters of unstiffened and stiffened plates are evaluated by means of FEA, and the obtained ultimate compressive strength values are used to construct the initial Kriging model. Initial imperfections (initial deflection of plate, Column-type and sider-ways initial deflection of stiffeners, ...), geometric crack characteristics (initial crack length, crack angle, crack location, ...) and material parameters (yielding stress, elastic modulus) can be considered as the input structural parameters, which can be appropriately described by normal or lognormal probability distributions according to the statistical analysis of ship survey. It should 
be pointed out that the shape of initial distortion for cracked plate is achieved by Python program in the finite element analysis.

4) Optimize the parameter of Gauss correlation function and construct the initial Kriging model. Based on current DoE points and the evaluated ultimate compressive strength values, the parameters of Gauss correlation function are optimized by means of the genetic algorithm, then Kriging model is constructed by the DACE toolbox in MATLAB (Lophaven et al., 2002). In this step, the correlation Gaussian model is chosen and the regression model is taken as first order polynomial regression function.

5) Calculate the Kriging prediction and evaluate the failure probability. Kriging prediction $\hat{G}(x)$ for all the sample points in population $S$ is calculated according to the built Kriging surrogate model, and the failure or safety status of all points is classified. Then the failure probability $P_{f}$ is estimated on the basis of a negative or null Kriging prediction and a total number of points in $S$.

6) Judge whether the convergence is satisfied. If the estimated failure probability satisfies the following relationship $\left|\left(P_{f(k)}-P_{f(k-1)}\right) / P_{f(k)}\right| \leq \eta$, the current Kriging model is considered to be accurate enough to estimate $P_{f}$, ending this iteration and going to step 8; otherwise, go to next step.

7) Enrich the new DoE point. If the stopping condition of step 6 is not met, the active learning procedure is performed to add the new DoE point by $\min (v(x))$ for $x \in S$, where $v(x)=|\hat{G}(x)| / \sigma_{\hat{G}}(x)$. Then go back to step 3 with the enriched DoE performing the next iteration.

8) End the iteration. If the convergence condition is satisfied, the iteration stops and then the final Kriging surrogate model and failure probability are obtained as the analysis results. 
The numerical procedure for probabilistic residual ultimate strength assessment based on Kriging-based Monte Carlo simulation method is divided into two main levels: MATLAB level and PYTHON level. The MATLAB main program controls the whole computational scheme automatically to run finite element analysis and to calculate the failure probability and reliability index. Finite element analysis controlled automatically by Python program can create finite element mesh, introduce uncertain crack and initial distortion, and evaluate residual ultimate strength without human intervention. Through the test analysis, the scheme of probabilistic residual ultimate strength assessment can run efficiently.

\section{Verifying computing model}

\subsection{Validation of ultimate strength analysis model}

Validation of ultimate strength analysis is carried out for the intact and cracked

unstiffened and stiffened plates. Square plates $($ length $\times$ width $\times$ thickness, $580 \times 500 \times 4.4$ $\mathrm{mm}$ ) with or without crack, derived from Paik et al. (2005), are adopted to study the ultimate strength characteristics of unstiffened plate. The unstiffened plate is simply supported on all free edges and subjected to uniaxial compressive loading. The ultimate strength values of intact plate and cracked plate obtained from the simulation are 109.1 $\mathrm{MPa}$ and 95.6 MPa as listed in Table. 4, which are approximately $4.3 \%$ and $3.2 \%$ higher than the test results, respectively. Difference between the simulated and experimental results could be caused by the applied material and boundary condition. On the other hand, stiffened plates (plate length $\times$ width $\times$ thickness, $3400 \times 850 \times 22 \mathrm{~mm}$; stiffener height $\times$ thickness, $250 \times 25 \mathrm{~mm}$ ) with or without crack, derived from Cui et al. (2017), are adopted to study the ultimate strength characteristics. According to Ref. (Cui et al., 2017), the stiffened plate is also simply supported on all free edges and subjected to uniaxial compressive loading. The predicted ultimate strength values are compared with Cui test 
results, as listed in Table. 4, which are well coincided with the reference results, verifying the accuracy of numerical models.

\subsection{Validation of reliability analysis method}

Next, an example is chosen to check the accuracy and efficiency of AK-MSC method. Consider a fourth order equation, where the performance function is expressed as,

$$
g(x)=2+\exp \left(-\frac{x_{1}^{2}}{10}\right)+\left(\frac{x_{1}}{5}\right)^{4}-x_{2}
$$

where $x_{1}$ and $x_{2}$ are normal random variables, $x_{1}-N(0.1,1), x_{2}-N(0.1,1)$.

For the prediction of Kriging model, the initial DoE points of size 8 are generated by uniformly sampling spanning the random variable space between the bounds \pm 3 standard deviation, as exhibited in Fig. 6. Monte Carlo population $S$ of size $n_{\mathrm{MC}}=5 \times 10^{5}$ points is generated based on the probability density functions of random variables, which is taken as candidate points to update Kriging and predict the failure probability. The convergence tolerance in terms of reliability index is set to $10^{-4}$.

Firstly, the initial DoE points of small size are employed to construct the initial Kriging model. The active learning method is adopted to identify the best next sample point for reconstructing Kriging surrogate model. As a new DoE point added, the Kriging metamodel is updated step by step, and the shape of predicted approximation tends rapidly towards the target limit state, as illustrated in Fig. 7. These new added DoE points are almost concentrated in the neighborhood of the true limit state, and the limit state is precisely approximated in an interesting localized subspace where the Monte Carlo population is located. This localized approximation could be achieved by adding the limited number of DoE points, which contributes to reach a faster convergence, as displayed in Fig. 8. In essence, the approximation achieved by Kriging model coincides well with the true limit state in the localized subspace covered by the Monte Carlo population, and the approximation becomes worse where there are no candidate points. 
Nonetheless, the inaccurate approximation locating at extremely weak densities of Monte Carlo sampling points has a negligible effect on failure probability, which can be neglected for the reliability analysis. The reliability analysis, failure probability and $N_{\text {call }}$ obtained by AK-MSC, RSM and MC method are summarized in Table 5. The comparison indicates that AK-MSC requires fewer calls to the performance function, and the prediction of reliability index is very accurate in comparison with the results of MC method.

\section{Results and discussion}

Firstly, a deterministic analysis is implemented to explore the influence of uncertain initial imperfections, cracking damages and material parameters on the ultimate strength reduction characteristics of cracked plates under longitudinal compression loading. Then, the evolution of failure probability and reliability index as function of each uncertain parameter is investigated. Furthermore, the probabilistic reliability analysis is carried out to evaluate the failure probability and reliability index of design objective for residual ultimate strength of cracked plate.

\subsection{Cracked unstiffened plate}

\subsubsection{Deterministic analysis for residual ultimate strength of cracked unstiffened plate}

As an example, the random variables considered in this analysis are the inclined angle, crack length, transverse distance, longitudinal distance and initial deflection (Cerik et al., 2013; Leonel et al., 2010, 2011; He et al., 2015; Riahi et al., 2010, 2011), which are modeled as independent lognormal random variables, as listed in Table 6. For the deterministic analysis, the mean values of random variables are chosen to evaluate the effect on the ultimate strength characteristics.

In order to quantify the reduction of ultimate strength, one of the five variable parameters is considered varied and the others are considered as mean values. Fig. 9 demonstrates the effect of each variable parameter on the average stress-strain 
relationship of cracked unstiffened plate under uniaxial compression. Here, the vertical coordinate $\sigma / \sigma_{y}$ denotes the non-dimensional of ultimate strength. The ultimate strength increases slightly as the inclined angle increases when the crack length and location keep constant, while the tangent stiffness and buckling strength are almost the same for varying inclined angle. Nevertheless, the crack length has a substantial influence on the residual ultimate strength, as it decreases to $70 \%$ when the crack length increases from $0.15 b$ to $0.60 b$. Furthermore, the tangent stiffness of initial loading path is almost the same, except for the crack length larger than $0.6 b$; while post-ultimate strength values of unloading path are affected severely. With respect to the longitudinal distance, it is obvious that the ultimate strength increases slightly and then decreases with the crack moving towards the short plate edge, which is closely related to the deflection modes in the form of regular buckling half-waves. However, the ultimate strength decreases markedly for the transverse distance cases. The ultimate strength decreases to $85 \%$ when the crack center moves from the center of plate to $30 \%$ of plate breadth, which is relatively more sensitive in comparison with the case of longitudinal distance. Moreover, the initial tangent stiffness during loading is almost the same for varying transverse distance, while the post-ultimate strength values decrease markedly when the transverse distance is more than $0.3 b$.

Fig. 10 displays the non-dimensional ultimate strengths of cracked plates with different initial deflection amplitudes ranging from slight level $0.01 \beta^{2} t$ to severe level $0.30 \beta^{2} t$. It is interesting that the tangent stiffness of cracked plate becomes smaller with the increase of initial deflection amplitude coefficient, but the post-ultimate strength value becomes larger. Overall, the initial deflection has a remarkable effect on both of the residual compressive strength and initial stiffness. Additionally, the effect of material parameters as yielding stress and elastic modulus (Shi et al., 2014; Omidali et al., 2018) on the residual ultimate strength is further investigated, as illustrated in Fig. 11. It is evident that 
the ultimate strength reduces dramatically with the decrease of yielding stress, while the tangent stiffness of initial loading path varies slightly. To the contrary, elastic modulus of material has significant effect on the tangent stiffness, whereas it has slight effect on the ultimate strength and post-ultimate strength.

\subsubsection{Probabilistic residual ultimate strength assessment of cracked unstiffened plate}

Kriging-based Monte Carlo simulation method is applied to evaluate probabilistic residual ultimate strength of cracked unstiffened plate considering five potential uncertain input variables (inclined angle, crack length, transverse distance, longitudinal distance and initial deflection). To construct initial Kriging model, the initial DoE points of size 20 are generated by uniformly sampling spanning the random variable space between the bounds \pm 3 standard deviation. For the analysis of failure probability, the convergence tolerance during the iterative procedure is taken as $10^{-4}$. The implicit limit state function is built by the difference between the resisting ultimate strength and applied compressive load according to Eq. (13). Due to the presence of crack, the applied compressive load of cracked plate is assumed to be $70 \%$ of ultimate strength of intact plate, so the loss factor $R$ is taken as 0.7 to evaluate the failure probability $p_{f}$ and reliability index $\beta$ of cracked plate using AK-MCS and classical response surface method (RSM). The accuracy and efficiency of two solution schemes are compared in terms of reliability index $\beta$ and FEM calls $N_{\text {call }}$, respectively.

FEM calls $N_{\text {call }}$ and reliability index $\beta$ obtained by two methods are summarized in Table 7. The comparison of reliability index $\beta$ manifests that these results are fairly consistent with each other, which demonstrates that AK-MCS is accurate for probabilistic ultimate strength assessment. However, it is obvious that far more FEM model calls are demanded for RSM analysis, while only less than 45 calls are required for the present AK-MCS. It can be concluded that probabilistic ultimate strength assessment for reliability index can be achieved by using AK-MCS with a smaller number of FEM 
model calls with comparison to RSM. Fig. 12 depicts the convergence histories of reliability index in terms of the number of iterations for AK-MCS when transverse distances of cracked plate are $0.50 b, 0.45 b, 0.40 b, 0.35 b$. In the first iteration, the initial DoE points of size 20 are required as the initial training sample set to construct initial Kriging model. During each iteration after the first, one best sample point identified by active learning approach is added into the training sample, and Kriging model is reconstructed iteratively. As the new DoE points added, the convergence is achieved rapidly with a smaller number of FEM model calls, and eventually the reliability index is obtained. As shown in Fig. 12, the convergence is basically reached in less than 30 iterations.

Fig. 13 and Fig. 14 display the evolution of failure probability $p_{f}$ and reliability index $\beta$ as function of ultimate strength loss factor $R$ when transverse distances of cracked plate are $0.50 b, 0.45 b, 0.40 b, 0.35 b$, respectively. As expected, the failure probability $p_{f}$ increases and the corresponding reliability index $\beta$ decreases with the increasing of ultimate strength loss factor $R$. Compared with the cases $(0.50 b$ and $0.45 b)$ of crack locating near the center of plate, it is found that failure probability and reliability index are almost the same for different ultimate strength loss factors. This means that it has much less effect on failure probability and reliability index when the crack locates in the vicinity of the center of plate in comparison with that locating around the edge of plate, which is consistent with deterministic analysis in Fig. 9(d). To provide a guideline for designer, a smaller target failure probability $p_{f}=0.001$, namely reliability index $\beta=3.049$, is considered. For this design level, the ultimate strength for each case of transverse distance is acceptable when loss factor $R$ is lower than $0.77,0.76,0.73,0.70$, respectively.

According to the deterministic and random analysis, the crack length and local plate deflection have the most serious effect on the residual ultimate strength of cracked plate 
for the uncertain initial imperfections and cracking damages. Therefore, the crack length and local plate deflection are chosen as the basic variables associated with the material parameters as yielding stress, elastic modulus (Shi et al., 2014; Omidali et al., 2018), which are modeled as independent lognormal random variables, as listed in Table 8. Probabilistic reliability analysis is also performed to investigate the influence of the above-mentioned parameters on ultimate strength characteristics of unstiffened plate using AK-MCS method. Fig. 15 illustrates the variation of failure probability $p_{f}$ and reliability index $\beta$ as function of ultimate strength loss factor $R$. It is evident that the reliability index $\beta$ decreases almost linearly with the increasing of ultimate strength loss factor $R$, and the corresponding failure probability $p_{f}$ increases almost log-linearly.

Sensitivity analysis could give a guideline for designers to place emphasis on more effective design variables in structural performance. Subsequently, sensitivity analysis of each potential parameter is investigated for the effect on the failure probability and reliability index. For this sensitivity analysis, the specific parameter is taken as mean value of the variable, and the others are considered as random variables. Fig. 16 illustrates the variation of failure probability $p_{f}$ and reliability index $\beta$ of each potential parameter as function of ultimate strength loss factor $R$ according to different combinations of random variables. As it can be seen, the crack length has the most significant effect on failure probability and reliability index in comparison with the other variables, which is consistent with the deterministic analysis. Moreover, the transverse distance has more obvious effect than longitudinal distance, which indicates that crack location close to long edge of the plate could result in more unfavorable conditions. Overall, the variation trend of probabilistic analysis corresponds to the deterministic analysis with the mean values of variables.

The sensitivity analysis is performed to clarify the influence of coefficients of variation $(\mathrm{COV})$ for uncertain input parameters on the probability reliability of residual ultimate 
strength. As a case study, the coefficients of variation are assumed as the same for all random variables varying from 0.06 to 0.24 . Fig. 17 displays the variation of failure probability $p_{f}$ and reliability index $\beta$ of residual ultimate strength for varying coefficients of variation. The results show that the reliability index $\beta$ decreases from 5.01 to 1.44 as the value of $\mathrm{COV}$ increases from 0.06 to 0.24 . Increasing the $\mathrm{COV}$, leads to more uncertainties of the probability model, and consequently lower reliability index and larger failure probability of the residual ultimate strength. Overall, failure probability $p_{f}$ and reliability index $\beta$ are sensitive to the $\mathrm{COV}$ of variables.

\subsection{Cracked stiffened plate}

\subsubsection{Deterministic analysis for residual ultimate strength of cracked stiffened plate}

Firstly, the uncertain initial imperfection and cracking damages of the stiffened plate are considered, which are modeled as independent lognormal random variables, as listed in Table 9. Similar as the unstiffened plate case, a deterministic analysis is implemented to explore the influence of uncertain variables. For the stiffener, the crack length keep constant $c=0.5 s$. Fig. 18 demonstrates the effect of varying crack parameters on ultimate strength characteristics of cracked stiffened plate. The ultimate strength reduces $16 \%$ when the inclined angle varies from $90^{\circ}$ to $30^{\circ}$, and the strain at the ultimate strength (ultimate strain) becomes larger with the decrease of inclined angle. However, the post-ultimate strength values during unloading regime are close for varying inclined angles. Apparently, the crack length significantly affects the structural response of stiffened plate in terms of buckling strength, ultimate strength, and reserve strength, which decreases dramatically with the increase of the crack length. Moreover, the ultimate strain at the collapse point reduces significantly with the increase of crack length.

For the longitudinal distance, it is obvious that the buckling strength, ultimate strength, reserve strength and initial stiffness are almost no change when the symmetrical crack of 
the stiffener moves from the center to the short edge of stiffened plate. However, transverse distance has relatively evident effect on ultimate strength compared with longitudinal distance. Furthermore, compared with the unstiffened plate, there is a smaller variation for cracked stiffened plate due to the presence of stiffener, regardless of the transverse and longitudinal distances cases.

Fig. 19(a) displays the reduction of the ultimate strength for cracked stiffened plates with different initial deflections. It is evident that ultimate strength characteristics of stiffened panel with single local plate deflection are identical with that of a superposition of three initial deflections, which have significant reduction compared with those with single column-type deflection or side-ways initial deflection. It can be concluded that the local plate deflection of stiffened plate has the most serious effect on the ultimate strength characteristics. The effect of magnitude of local plate deflection on ultimate strength characteristics is further investigated in Fig. 19(b). Apparently, it has a slight effect on the ultimate strength, but affects the structural rigidity significantly. Furthermore, the ultimate strain at the collapse point increases significantly with the increase of initial deflection amplitude coefficient, and meanwhile the post-ultimate strength value during unloading regime also increases.

Additionally, the effect of material parameters is considered including the yielding stress and elastic modulus, as displayed in Fig. 20. It shows that yielding stress has a significant effect on the ultimate strength and post-ultimate strength, while elastic modulus affects slightly. Contrarily, the yielding stress has slight effect on tangent stiffness, whereas elastic modulus affects remarkably.

\subsubsection{Probabilistic residual ultimate strength assessment of cracked stiffened plate}

Probabilistic reliability analysis is also performed to investigate the influence of uncertain cracking damages and initial deflection on ultimate strength characteristics of stiffened plate. It should be noted that only the local plate deflection is taken as a random 
variable for the initial distortion according to the deterministic analysis. As before, the initial DoE points of size 20 are generated to construct the initial Kriging model, and the convergence tolerance during the iterative procedure is also taken as $10^{-4}$. Considering a more common circumstance, it is assumed that a crack exists in the stiffener. Due to the presence of crack, the design ultimate strength of cracked plate is lower than that of intact plate, so the ultimate strength loss factor $R$ is taken as 0.6 as an example to evaluate the failure probability $p_{f}$ and reliability index $\beta$ of cracked stiffened plate.

The numerical implementation of probabilistic reliability analysis using AK-MCS method is relatively easy to achieve, since it only needs to run a limited number of deterministic finite element analysis in the random space. Table 10 lists the reliability index $\beta$ and FEM calls $N_{\text {call }}$ using AK-MCS method when the crack length in stiffener is $0.3 s, 0.4 s, 0.5 s, 0.6 s$. Meanwhile, the classical RSM approach is also performed to illustrate the accuracy and efficiency of probabilistic reliability analysis adopted in this study. The reliability indexes obtained by two solution schemes agree well with each other, which indicates that the proposed probabilistic reliability analysis approach is accurate enough to evaluate residual ultimate strength of cracked stiffened plate. When the convergence of reliability analysis is achieved, the number of FEM calls $N_{\text {call }}$ achieved by two solution schemes is compared in Table 10. Concerning RSM analysis, it requires an extremely high number of FEA calls compared with AK-MCS analysis, which makes it impossible to deal with the reliability analysis question requiring to call numerical implicit model. This is attributed to the fact that implicit model arises numerical errors when running finite element analysis, especially for the nonlinear analysis. Fig. 21 illustrates the convergence histories of reliability index in terms of the number of iterations for AK-MCS. As the new DoE point added, the convergence is achieved rapidly with less than 35 iterations, and eventually the reliability index is obtained. 
Fig. 22 and Fig. 23 display the evolution of failure probability $p_{f}$ and reliability index $\beta$ as function of ultimate strength loss factor $R$ when the crack length in stiffener is $0.3 \mathrm{~s}$, $0.4 \mathrm{~s}, 0.5 \mathrm{~s}, 0.6 \mathrm{~s}$, respectively. Apparently, the failure probability $p_{f}$ increases almost log-linearly with the increasing of ultimate strength loss factor $R$ for all cases, and corresponding reliability index $\beta$ decreases almost linearly. Similarly, a target failure probability $p_{f}=0.001$ is considered, namely reliability index $\beta=3.049$, the ultimate strength for each case is acceptable when loss factor $R$ is lower than $0.48,0.45,0.42,0.40$, respectively. Similar as unstiffened plate case, a probabilistic characteristic for the stiffened plate with basic variables such as crack length, local plate deflection, yielding stress and elastic modulus (Table 11), is further investigated. The evolution of failure probability $p_{f}$ and reliability index $\beta$ as function of ultimate strength loss factor $R$ is displayed in Fig. 24. It is evident that the reliability index $\beta$ decreases almost linearly with the increasing of ultimate strength loss factor $R$, and the corresponding failure probability $p_{f}$ increases almost log-linearly.

Sensitivity analysis is performed to clarify the correlation of failure probability and reliability index with each potential parameter. For this sensitivity analysis, the specific parameter is taken as mean value of the variable, and the others are considered as random variables. Fig. 25 illustrates the variation of failure probability $p_{f}$ and reliability index $\beta$ of each potential parameter as function of ultimate strength loss factor $R$. Similar as the cracked unstiffened plate, the crack length in stiffened plate has the most significant effect on failure probability and reliability index, closely followed by inclined angle, which is consistent with the deterministic analysis. Furthermore, crack location and initial deflection have slight influence on the failure probability and reliability index. It indicates that crack length is the most critical factor in determining the probabilistic reliability of cracked plate. 
Sensitivity analysis is further investigated by changing the COV of each variable varying from 0.08 to 0.30 . Fig. 26 displays the sensitivity of failure probability $p_{f}$ and reliability index $\beta$ as a function of $\mathrm{COV}$. It is obvious that the probability reliability of residual ultimate strength is extremely sensitive to the COV. This is due to the fact that larger values of standard deviations produce high level of uncertainty, which leads to the reliability index $\beta$ dramatically decreases and the corresponding failure probability $p_{f}$ sharply increases. For example, reliability index $\beta$ decreases from 3.79 to 1.65 as the value of $\mathrm{COV}$ increases from 0.10 to 0.30 . Therefore, the designer should make a comprehensive study on the potential uncertain parameters so as to consider their accurate statistics in design.

\section{Conclusions}

This paper proposes a reliability analysis approach to evaluate the probabilistic ultimate strength of cracked unstiffened/stiffened plates by coupling nonlinear finite element analysis and Kriging-based reliability method. A numerical simulation scheme is established to evaluate residual ultimate strength of cracked plates under uniaxial compression loading, considering the influence of uncertain initial imperfections, cracking damages and material parameters. To improve efficiency of the assessment, Kriging-based Monte Carlo simulation method combined with active learning strategy is adopted to solve the reliability problem of ultimate strength.

Firstly, a deterministic analysis is implemented to explore the influence of uncertain initial deflection, cracking damages and material parameters on the ultimate strength reduction characteristics of cracked plates under uniaxial compression loading. The effect on ultimate strength, tangent stiffness, buckling strength and ultimate strain is studied systematically. Results demonstrate that crack length and transverse distance of crack and yield stress have significant influence on the residual compressive strength, whereas the initial stiffness varies slightly; the initial deflection and elastic modulus have remarkable 
effect on initial stiffness. The ultimate strain becomes lesser with the increase of damage level, whereas becomes larger with the increase of initial deflection.

Then, the evolution of failure probability and reliability index as function of each uncertain parameter is investigated. The convergence histories of reliability index illustrate that probabilistic ultimate strength assessment can be achieved by AK-MCS with a smaller number of FEM calls. Sensitivity analysis of all uncertain parameters on the reliability index and failure probability is studied, and the result reveals that its variation tendency is consistent with deterministic analysis. Furthermore, the probabilistic reliability analysis is carried out to evaluate the failure probability and reliability index of design objective for ultimate strength of cracked plate. Results show that crack length has the most significant effect on failure probability and reliability index, which is consistent with the deterministic analysis. It can be concluded that the proposed probabilistic ultimate strength assessment method is accurate and efficient to deal with structural reliability analysis of cracked plates.

\section{Acknowledgements}

The present work is supported by the National Natural Science Foundation of China (Grant Nos. 51879248 and 51609089) and the China Postdoctoral Science Foundation (Grant No. 2016M592338).

\section{Appendix A}

In order to consider the effect of distribution type on the probability reliability of residual ultimate strength. The probability density functions (PDF) are assumed to be lognormal and normal distributions with the same values of mean and standard deviation, and a comparison of lognormal and normal distribution types is made in Fig. A1. It is noted that the influence is evident when the failure probability is small, while the discrepancies are small for cases of larger failure probability. However, for fitting a group of random variables, different distribution types generally correspond with 
different values of mean and COV. Hence, the designer shall do a comprehensive study for fitting the distribution of random variable.

\section{References}

Amlashi, H.K., Moan, T., 2008. Ultimate strength analysis of a bulk carrier hull girder under alternate hold loading condition-A case study: Part 1: Nonlinear finite element modelling and ultimate hull girder capacity. Mar. Struct. 21(4), 327-352.

Bayatfar, A., Khedmati, M.R., Rigo, P., 2014. Residual ultimate strength of cracked steel unstiffened and stiffened plates under longitudinal compression. Thin Walled Struct. 84, 378-392.

Benson, S., Downes, J., Dow, R.S., 2013. Compartment level progressive collapse analysis of lightweight ship structures. Mar. Struct. 31, 44-62.

Cerik, B.C., Shin, H.K., Cho, S.R., 2013. Probabilistic ultimate strength analysis of submarine pressure hulls. Int. J. Nav. Archit. Ocean Eng. 5(1), 101-115.

Chen N.Z., Guedes Soares C., 2007. Reliability assessment of post-buckling compressive strength of laminated composite plates and stiffened panels under axial compression. Int J Solids Struct. 44(22-23):7167-82.

Cui, C., Yang, P., Li, C., Xia, T., 2017. Ultimate strength characteristics of cracked stiffened plates subjected to uniaxial compression. Thin Walled Struct. 113, 27-38.

Cui, C., Yang, P., Xia, T., Du, J., 2016. Assessment of residual ultimate strength of cracked steel plates under longitudinal compression. Ocean Eng. 121, 174-183.

Cui, J., Wang, D., Ma, N., 2019. Case studies on the probabilistic characteristics of ultimate strength of stiffened panels with uniform and non-uniform localized corrosion subjected to uniaxial and biaxial thrust. Int. J. Nav. Archit. Ocean Eng. 11(1), 97-118.

Echard, B., Gayton, N., Lemaire, M., 2011. AK-MCS: an active learning reliability method combining kriging and monte carlo simulation. Struct. Saf. 33(2), 145-154. 
Elhanafi, A.S., Leheta, H.W., Badran, S.F., 2017. Time-variant reliability analysis of novel deck and bottom panels. Ocean Eng. 133, 73-88.

Faravelli, L., 1989. Response-surface approach for reliability analysis. J. Eng. Mech. 115(12), 2763-2781.

Faulkner, D., 1991. Application of reliability theory in submarine design. In: C.S. Smith and R.S. Dow, eds. Advances in Marine Structures-2. Dunfermline, Scotland, U.K 21-24 May 1991. London: Elsevier Applied Science Publishers, pp.566-230.

Gaspar, B., Naess, A., Leira, B.J., Soares, C.G., 2012. System reliability analysis of a stiffened panel under combined uniaxial compression and lateral pressure loads. Struct. Saf. 39, 30-43.

Gao, D.W., Shi, G.J., Wang, D.Y., 2012. Residual ultimate strength of hull structures with crack and corrosion damage. Eng. Fail. Anal. 25, 316-328.

He, W., Liu, J., Xie, D., 2014. Numerical study on fatigue crack growth at a web-stiffener of ship structural details by an objected-oriented approach in conjunction with ABAQUS. Mar. Struct. 35, 45-69.

He, W., Liu, J., Xie, D., 2015. Probabilistic life assessment on fatigue crack growth in mixed-mode by coupling of kriging model and finite element analysis. Eng. Fract. Mech. 139, 56-77.

He W, Liu L.C., Yang J.P., 2013. Reliability analysis of stiffened tank-roof stability with multiple random variables using minimum distance and Lagrange methods. Eng Fail Anal 32:304-311.

He, W., Wang, C., Deng, J., Xie, D., Zhang, Z., 2020. Effect of single tensile overload on fatigue crack growth behavior based on plastically dissipated energy and critical distance theory. Eng. Fract. Mech. 223, 106744.

ISSC Committee III.1, 2012. Report: ultimate strength. In: Proceedings of the $18^{\text {th }}$ International Ship and Offshore Structures Congress (ISSC), pp. 285-363. 
Kaymaz, I., 2005. Application of kriging method to structural reliability problems. Struct. Saf. 27(2), 133-151.

Kharghani, N., Soares, C.G., Tsouvalis, N.G., 2019. Experimental and numerical study of the bolt reinforcement of a composite-to-steel butt-joint under three-point bending test. Mar. Struct. 63, 384-403.

Leonel E., Chateauneuf A., Venturini W., Bressolette P., 2010. Coupled reliability and boundary element model for probabilistic fatigue life assessment in mixed mode crack propagation, Int. J. Fatigue 32, 1823-1834.

Leonel E.D., Beck A.T., Venturini W.S., 2011. On the performance of response surface and direct coupling approaches in solution of random crack propagation problems, Struct. Saf. 33, 261-274.

Li, C., Ren, H., Zhu, Z., Soares, C.G., 2018. Numerical investigation on the ultimate strength of aluminium integrally stiffened panels subjected to uniaxial compressive load. Thin-Walled Struct. 127, 221-234.

Lophaven, S., Nielsen, H., Sondergaard, J., 2002. A MATLAB Kriging toolbox. Technical University of Denmark. Kongens Lyngby, Technical Report No. IMM-TR-2002-12.

Luo, X., Li, X., Zhou, J., Cheng, T., 2012. A kriging-based hybrid optimization algorithm for slope reliability analysis. Struct. Saf. 34(1), 401-406.

Margaritis Y., Toulios M., 2012. The ultimate and collapse response of cracked stiffened plates subjected to uniaxial compression. Thin-Walled Struct. 50, 157-173.

Matheron, G., 1973. The intrinsic random functions and their applications. Adv. Appl. Probab. 5(3), 439-468.

Omidali, M., Khedmati, M.R., 2018. Reliability-based design of stiffened plates in ship structures subject to wheel patch loading. Thin-Walled Struct. 127, 416-424. 
Paik, J.K., Kumar, Y.V.S., Lee, J.M., 2005. Ultimate strength of cracked plate elements under axial compression or tension. Thin-Walled Struct. 43, 237-272.

Paik, J.K., 2008. Residual ultimate strength of steel plates with longitudinal cracks under axial compression-experiments. Ocean Eng. 35(17-18), 1775-1783.

Paik J.K., 2009. Residual ultimate strength of steel plates with longitudinal cracks under axial compression-Nonlinear finite element method investigations. Ocean Eng. 36(3-4), 266-276.

Papadrakakis, M., Papadopoulos, V., Lagaros, N.D., 1996. Structural reliability analyis of elastic-plastic structures using neural networks and monte carlo simulation. Comput. Method. Appl. Mech. Eng. 136(1-2), 145-163.

Riahi H., Bressolette P., A. Chateauneuf, 2010. Random fatigue crack growth in mixed mode by stochastic collocation method, Eng. Fract. Mech. 77, 3292-3309.

Riahi H., Bressolette Ph., Chateauneuf A., Bouraoui Ch., Fathallah R, 2011. Reliability analysis and inspection updating by stochastic response surface of fatigue cracks in mixed mode. Eng Struct 33,3392-401.

Seyffert, H.C., Troesch, A.W., Collette, M.D., 2019. Combined stochastic lateral and in-plane loading of a stiffened ship panel leading to collapse. Mar. Struct. 67, 102620.

Silva, J.E., Garbatov, Y., Soares, C.G., 2013. Ultimate strength assessment of rectangular steel plates subjected to a random localised corrosion degradation. Eng. Struct. 52, 295-305.

Saad-Eldeen, S., Garbatov, Y., Soares, C.G., 2018. Structural capacity of plates and stiffened panels of different materials with opening. Ocean Eng. 167, 45-54.

Shi, X.H., Teixeira, A.P., Zhang, J., Guedes Soares, C., 2014. Structural reliability analysis based on probabilistic response modelling using the maximum entropy method. Eng. Struct. $70(0), 106-116$. 
Shi, X.H., Zhang, J., Soares, C.G., 2017. Experimental study on collapse of cracked stiffened plate with initial imperfections under compression. Thin-Walled Struct. 114, 39-51.

Shi, X.H., Zhang, J., Soares, C.G., 2019. Numerical assessment of experiments on the residual ultimate strength of stiffened plates with a crack. Ocean Eng. 171, 443-457.

Vapnik, V., 1982. Estimation of Dependences Based on Empirical Data: Springer Series in Statistics (Springer Series in Statistics). Secaucus, NJ, USA: Springer-Verlag, New York, Inc.; ISBN 0387907335.

Wang, F., Paik, J. K., Kim, B. J., Cui, W., Hayat, T., Ahmad, B., 2015. Ultimate shear strength of intact and cracked stiffened panels. Thin-Walled Struct. 88, 48-57.

Wang, R., Shenoi, R.A., Sobey, A., 2018. Ultimate strength assessment of plated steel structures with random pitting corrosion damage. J. Constr. Steel Res.143, 331-342.

Xia, T., Yang, P., Hu, K., Cui, C., 2018. Combined effect of imperfections on ultimate strength of cracked plates under uniaxial compression. Ocean Eng. 150, 113-123.

Xia, T., Yang, P., Li, C., Hu, K., 2019. Numerical research on residual ultimate strength of ship hull plates under uniaxial cyclic loads. Ocean Eng. 172, 385-395.

Xu, M.C., Garbatov, Y., Soares, C.G., 2014. Residual ultimate strength assessment of stiffened panels with locked cracks. Thin-Walled Struct. 85, 398-410.

Xu, S., Liu, B., Garbatov, Y., Wu, W., Soares, C.G., 2019. Experimental and numerical analysis of ultimate strength of inland catamaran subjected to vertical bending moment. Ocean Eng. 188, 106320.

Yu, C.L., Chen, Y.T., Yang, S., Liu, Y., Lu, G.C., 2018. Ultimate strength characteristic and assessment of cracked stiffened panel under uniaxial compression. Ocean Eng. $152,6-16$. 
Yang, N., Das, P.K., Blake, J.I.R., Sobey, A.J., Shenoi, R.A., 2013. The application of reliability methods in the design of tophat stiffened composite panels under in-plane loading. Mar. Struct. 32, 68-83. 


\section{LIST OF TABLES}

Table 1 Study on ultimate strength of cracked unstiffened and stiffened plates.

Table 2 Geometric and material properties of unstiffened and stiffened plates.

Table 3 Residual ultimate strength of cracked plates with varying mesh size.

Table 4 Validation of ultimate strength for unstiffened and stiffened plates.

Table 5 Comparison of reliability analysis.

Table 6 Random variables of crack and deflection for unstiffened plate.

Table 7 Results of reliability index for unstiffened plate.

Table 8 Probabilistic characteristics of basic variables for unstiffened plate.

Table 9 Random variables of crack and deflection for stiffened plate.

Table 10 Results of reliability index for stiffened plate.

Table 11 Probabilistic characteristics of basic variables for stiffened plate. 


\section{TABLES}

\section{Table 1}

Study on ultimate strength of cracked unstiffened and stiffened plates.

\begin{tabular}{|c|c|c|}
\hline References & Cracked unstiffened/stiffened plates & Main influence variables \\
\hline Paik (2008) & Unstiffened plates & Crack orientation and crack location \\
\hline Paik (2009) & Unstiffened plates & $\begin{array}{l}\text { Crack orientation, location, size, plate } \\
\text { thickness, and plate aspect ratio }\end{array}$ \\
\hline Xia et al. (2018) & Unstiffened plates & $\begin{array}{l}\text { Initial deflections, welding residual } \\
\text { stresses, crack length and location }\end{array}$ \\
\hline Bayatfar et al. (2014) & Unstiffened/stiffened plates & Crack length and location \\
\hline $\begin{array}{l}\text { Shi et al. (2017, } \\
\text { 2019) }\end{array}$ & Stiffened plates & $\begin{array}{l}\text { Initial distortions, and varying crack } \\
\text { size, orientation and location }\end{array}$ \\
\hline Li et al. (2018) & Stiffened plates & $\begin{array}{l}\text { Initial distortions, material yield } \\
\text { strength and residual stresses. }\end{array}$ \\
\hline Yu et al. (2018) & Stiffened plates & Crack length, location and orientation \\
\hline Xu et al. (2014) & Stiffened plates & $\begin{array}{l}\text { Plate aspect ratio, crack length, } \\
\text { orientation and location }\end{array}$ \\
\hline Wang et al. (2018) & Stiffened plates & $\begin{array}{l}\text { Initial deflection, slenderness and } \\
\text { aspect ratios, and boundary conditions }\end{array}$ \\
\hline Cui et al. (2018) & Stiffened plates & $\begin{array}{l}\text { Crack length, crack location and plate } \\
\text { thickness }\end{array}$ \\
\hline
\end{tabular}

\section{Table 2}

Geometric and material properties of unstiffened and stiffened plates.

\begin{tabular}{l}
\hline Properties \\
\hline Yield stress of AH36 steel, $\sigma_{\mathrm{y}}=393.4 \mathrm{MPa}$ \\
Elastic modulus, $E=209.22 \mathrm{GPa}$ \\
Possion's ratio, $v=0.3$ \\
Plate length, $a=2550 \mathrm{~mm}$ \\
Plate breath, $\mathrm{b}=850 \mathrm{~mm}$ \\
Plat thickness, $t=13 \mathrm{~mm}$ \\
Stiffener, $h_{\mathrm{w}} \times t_{\mathrm{w}}=200 \times 15 \mathrm{~mm}$
\end{tabular}




\section{Table 3}

Residual ultimate strength of cracked plates with varying mesh size.

\begin{tabular}{ccccc}
\hline Mesh size $(\mathrm{mm})$ & 10 & 30 & 50 & 70 \\
\hline Unstiffened plate (MPa) & 219.97 & 220.18 & 220.81 & 221.29 \\
Stiffened plate (MPa) & 231.07 & 232.44 & 233.31 & 237.44 \\
\hline
\end{tabular}

\section{Table 4}

Validation of ultimate strength for unstiffened and stiffened plates.

\begin{tabular}{cccccc}
\hline \multirow{2}{*}{$\begin{array}{c}\text { Unstiffened/ } \\
\text { Stiffened plates }\end{array}$} & \multicolumn{2}{c}{ Unstiffened (Paik, 2008) } & & \multicolumn{2}{c}{ Stiffened (Cui, 2017) } \\
\cline { 2 - 3 } \cline { 5 - 6 } & Intact & Cracked & & Intact & Cracked \\
\hline Simulation(MPa) & 109.1 & 95.6 & & 208.1 & 190.0 \\
Reference(MPa) & 104.6 & 92.6 & & 204.2 & 188.9 \\
error & $4.3 \%$ & $3.3 \%$ & & $1.9 \%$ & $0.6 \%$ \\
\hline
\end{tabular}

\section{Table 5}

Comparison of reliability analysis.

\begin{tabular}{cccccc}
\hline Reliability method & $N_{\text {call }}$ & $P_{f}\left(10^{-3}\right)$ & Error/\% & $\beta$ & Error/\% \\
\hline Monte Carlo & $10^{7}$ & 2.531 & $/$ & 2.803 & $/$ \\
RSM & 31 & 1.878 & 25.80 & 2.898 & 3.389 \\
AK-MC & 14 & 2.539 & 0.316 & 2.802 & 0.036 \\
\hline
\end{tabular}

\section{Table 6}

Random variables of crack and deflection for unstiffened plate.

\begin{tabular}{ccccc}
\hline Variable & Symbol & Distribution & Mean & COV \\
\hline Inclined angle & $\theta$ & Lognormal & 90 & 0.15 \\
Crack length & $l$ & Lognormal & $0.3 l$ & 0.20 \\
Longitudinal distance & $h$ & Lognormal & $0.5 a$ & 0.10 \\
Transverse distance & $v$ & Lognormal & $0.5 b$ & 0.10 \\
Initial deflection & $\alpha$ & Lognormal & 0.1 & 0.20 \\
\hline
\end{tabular}




\section{Table 7}

Results of reliability index for unstiffened plate.

\begin{tabular}{|c|c|c|c|c|c|c|c|c|}
\hline \multirow{2}{*}{ Case } & \multicolumn{2}{|c|}{$v=0.50 \mathrm{~b}$} & \multicolumn{2}{|c|}{$v=0.45 b$} & \multicolumn{2}{|c|}{$\nu=0.40 b$} & \multicolumn{2}{|c|}{$\nu=0.35 b$} \\
\hline & $\beta$ & $N_{\text {call }}$ & $\beta$ & $N_{\text {call }}$ & $\beta$ & $N_{\text {call }}$ & $\beta$ & $N_{\text {call }}$ \\
\hline Kriging & 3.431 & 45 & 3.386 & 45 & 3.136 & 43 & 2.773 & 39 \\
\hline RSM & 3.390 & 434 & 3.334 & 626 & 3.111 & 158 & 2.709 & 410 \\
\hline
\end{tabular}

\section{Table 8}

Probabilistic characteristics of basic variables for unstiffened plate.

\begin{tabular}{cccccc}
\hline Variable & Symbol & Distribution & Mean & COV & Unit \\
\hline Crack length & $l$ & Lognormal & $0.3 l$ & 0.20 & $\mathrm{~mm}$ \\
Initial deflection & $\alpha$ & Lognormal & 0.1 & 0.20 & - \\
Yielding stress & $\sigma$ & Lognormal & 393.4 & 0.08 & $\mathrm{MPa}$ \\
Elastic modulus & $E$ & Lognormal & 209.22 & 0.08 & $\mathrm{GPa}$ \\
\hline
\end{tabular}

\section{Table 9}

Random variables of crack and deflection for stiffened plate.

\begin{tabular}{ccccc}
\hline Variable & Symbol & Distribution & Mean & COV \\
\hline Inclined angle & $\theta$ & Lognormal & 90 & 0.15 \\
Crack length & $l$ & Lognormal & $0.4 l$ & 0.20 \\
Longitudinal distance & $h$ & Lognormal & $0.5 a$ & 0.10 \\
Transverse distance & $v$ & Lognormal & $0.5 b$ & 0.10 \\
Initial deflection & $\alpha$ & Lognormal & 0.1 & 0.20 \\
\hline
\end{tabular}

\section{Table 10}

Results of reliability index for stiffened plate.

\begin{tabular}{|c|c|c|c|c|c|c|c|c|}
\hline \multirow{2}{*}{ Case } & \multicolumn{2}{|c|}{$c=0.3 s$} & \multicolumn{2}{|c|}{$c=0.4 s$} & \multicolumn{2}{|c|}{$c=0.5 s$} & \multicolumn{2}{|c|}{$c=0.6 s$} \\
\hline & $\beta$ & $N_{\text {call }}$ & $\beta$ & $N_{\text {call }}$ & $\beta$ & $N_{\text {call }}$ & $\beta$ & $N_{\text {call }}$ \\
\hline Kriging & 3.477 & 55 & 3.168 & 39 & 2.872 & 40 & 2.577 & 37 \\
\hline RSM & 3.411 & 1154 & 3.177 & 242 & 2.841 & 506 & 2.523 & 554 \\
\hline
\end{tabular}




\section{Table 11}

Probabilistic characteristics of basic variables for stiffened plate.

\begin{tabular}{cccccc}
\hline Variable & Symbol & Distribution & Mean & COV & Unit \\
\hline Crack length & $l$ & Lognormal & $0.4 l$ & 0.20 & $\mathrm{~mm}$ \\
Initial deflection & $\alpha$ & Lognormal & 0.1 & 0.20 & - \\
Yielding stress & $\sigma$ & Lognormal & 393.4 & 0.08 & $\mathrm{MPa}$ \\
Elastic modulus & $E$ & Lognormal & 209.22 & 0.08 & $\mathrm{GPa}$ \\
\hline
\end{tabular}




\section{LIST OF FIGURES}

Fig. 1. Cracked plate elements: (a) unstiffened plate; (b) stiffened plate.

Fig. 2. Boundary and loading conditions for cracked plates: (a) unstiffened plate; (b) stiffened plate.

Fig. 3. Typical initial distortions for cracked plates (with magnification of $10 \times$ ): (a) unstiffened plate; (b) stiffened plate.

Fig. 4. Typical mesh generation for cracked plates: (a) unstiffened plate; (b) stiffened plate.

Fig. 5. Flowchart of the Kriging method for modeling probabilistic residual ultimate strength.

Fig. 6. Initial DoE points in an interesting localized subspace.

Fig. 7. Approximation by AK-MCS by adding new DoE point.

Fig. 8. Convergence histories for the Kriging result.

Fig. 9. Average stress-strain curves for different crack cases of unstiffened plates: (a) incline angle; (b) crack length; (c) longitudinal distance; (d) transverse distance.

Fig. 10. Average stress-strain curves of cracked unstiffened plate with varying initial deflection amplitude coefficient $\alpha$.

Fig. 11. Average stress-strain curves of cracked unstiffened plate with varying material parameters: (a) yielding stress; (b) elastic modulus.

Fig. 12. Convergence histories of reliability indexes for cases with different transverse distances.

Fig. 13. Evolution of failure probability with different transverse distances.

Fig. 14. Evolution of reliability index with different transverse distances.

Fig. 15. Evolution of reliability index and failure probability of unstiffened plate. 
Fig. 16. Sensitivity analysis of each random variable on reliability index and failure probability of unstiffened plate.

Fig. 17. Sensitivity analysis of COV on reliability index and failure probability of unstiffened plate.

Fig. 18. Average stress-strain curves for different crack cases of stiffened plates: (a) incline angle; (b) crack length; (c) longitudinal distance; (d) transverse distance.

Fig. 19. Average stress-strain curves of cracked stiffened plate with different initial deflections.

Fig. 20. Average stress-strain curves of cracked stiffened plate with varying material parameters: (a) yielding stress; (b) elastic modulus.

Fig. 21. Convergence histories of reliability indexes for cases with different crack lengths in stiffener.

Fig. 22. Evolution of failure probability with different crack lengths in stiffener.

Fig. 23. Evolution of reliability index with different crack lengths in stiffener.

Fig. 24. Evolution of reliability index and failure probability of stiffened plate.

Fig. 25. Sensitivity analysis of each random variable on reliability index and failure probability of stiffened plate.

Fig. 26. Sensitivity analysis of COV on reliability index and failure probability of stiffened plate.

Fig. A1. Sensitivity analysis of distribution type on reliability index and failure probability of unstiffened plate. 


\section{FIGURES}

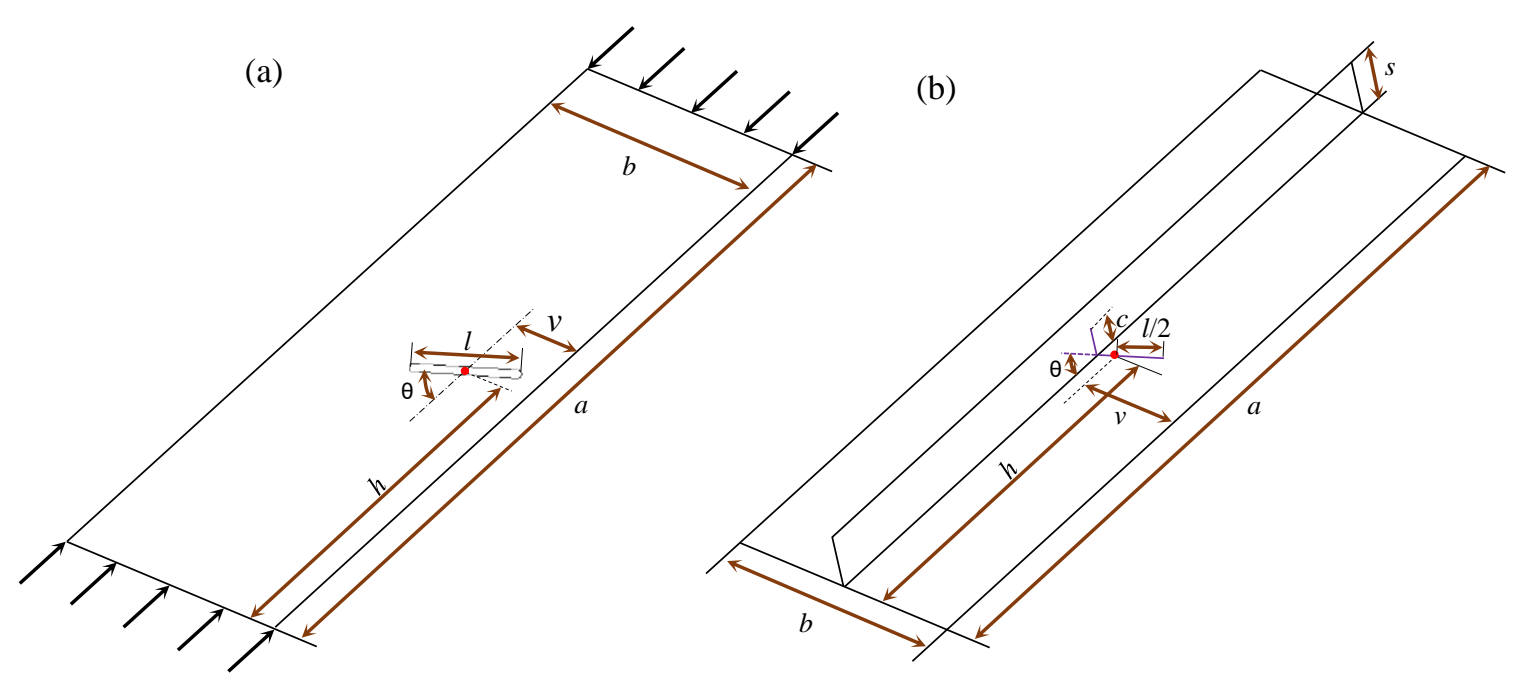

Fig. 1. Cracked plate elements: (a) unstiffened plate; (b) stiffened plate. 
(a)

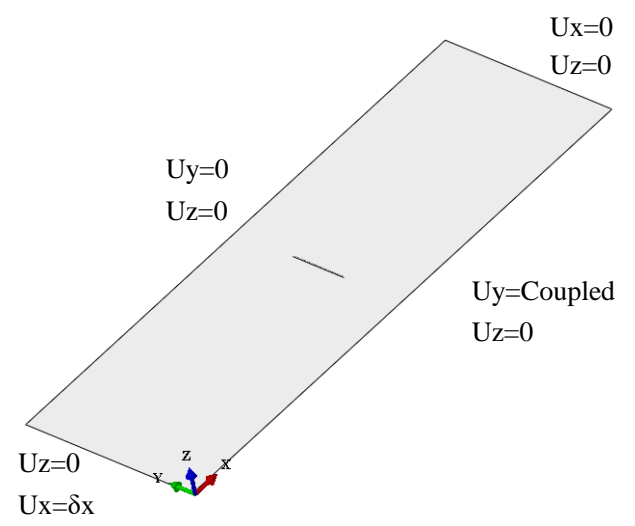

(b)

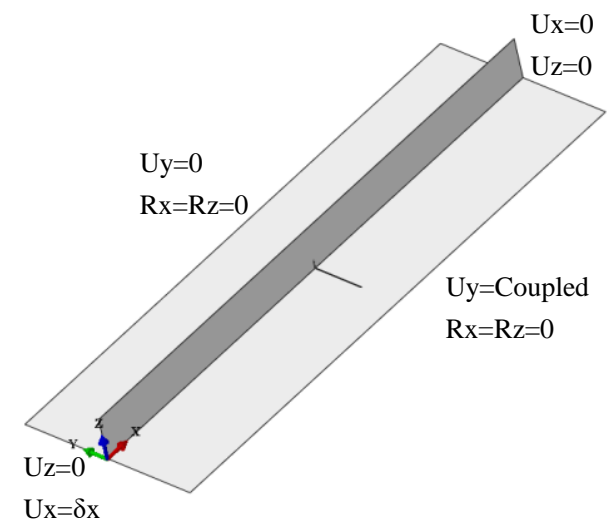

Fig. 2. Boundary and loading conditions for cracked plates: (a) unstiffened plate; (b) stiffened plate. 


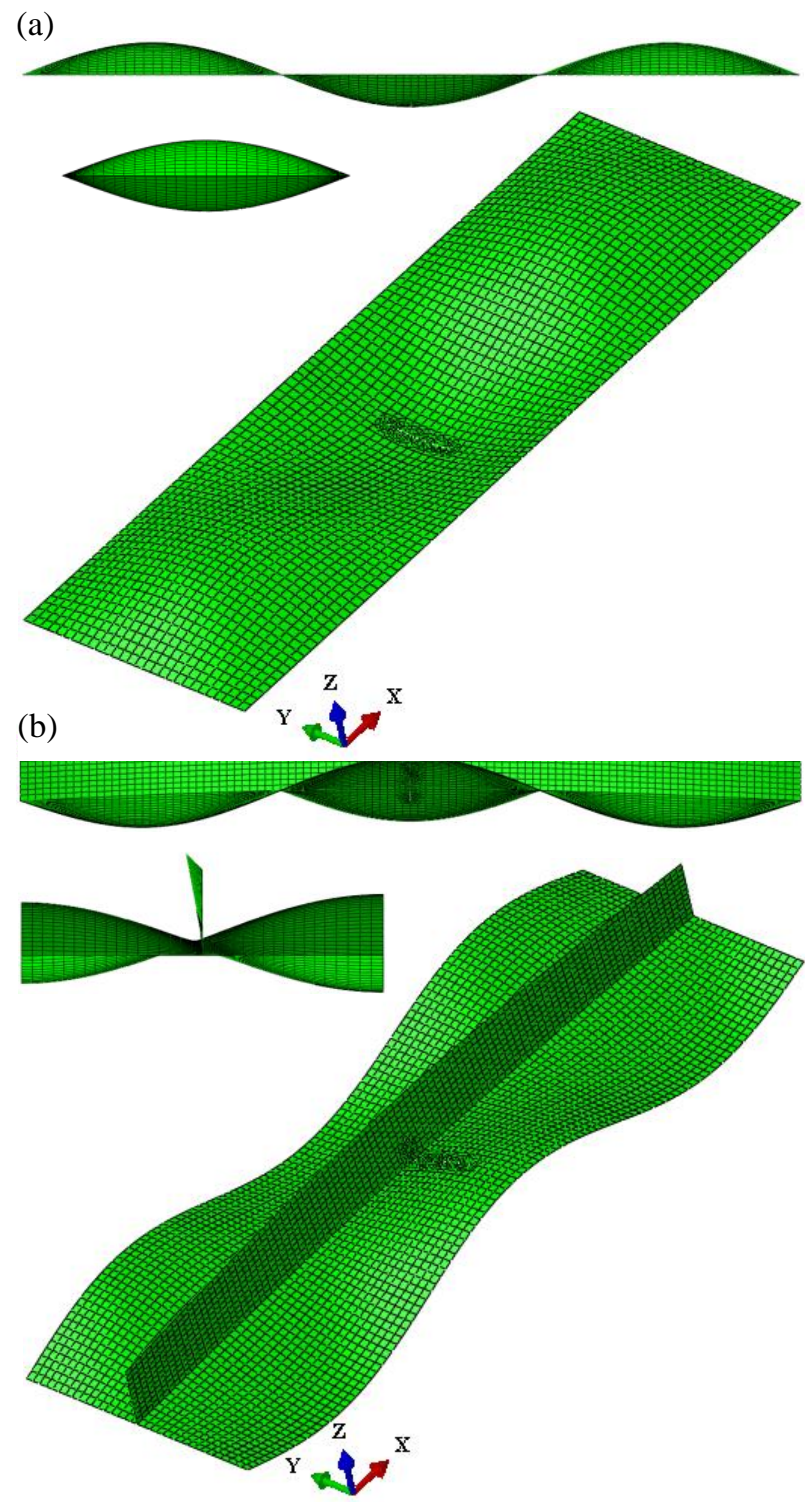

Fig. 3. Typical initial distortions for cracked plates (with magnification of $10 \times$ ): (a) unstiffened plate; (b) stiffened plate. 

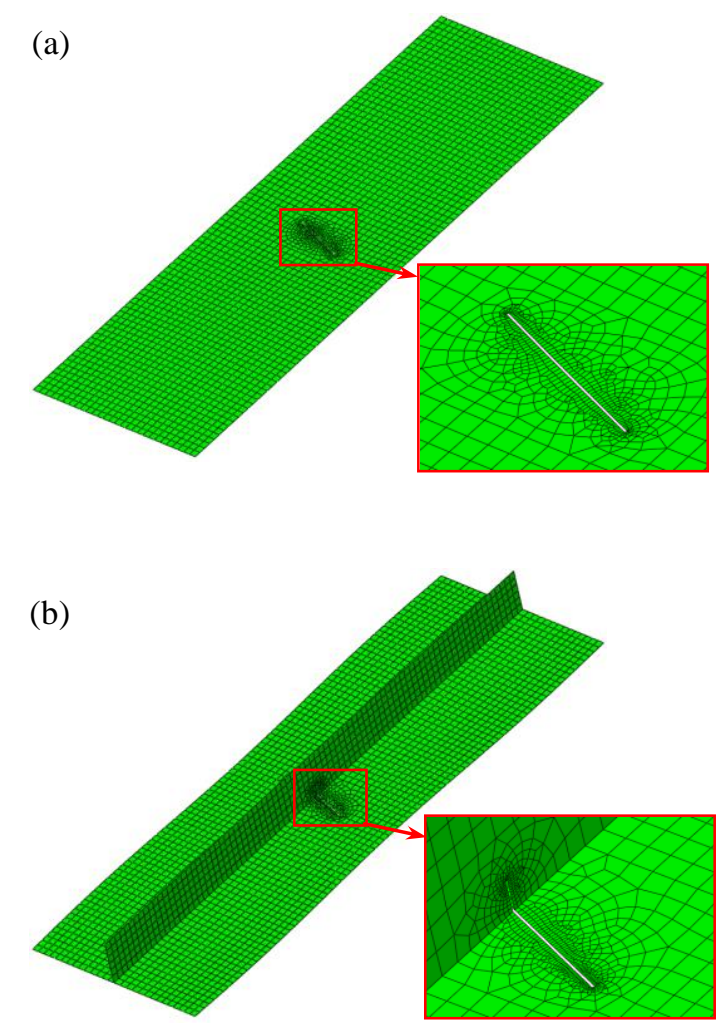

Fig. 4. Typical mesh generation for cracked plates: (a) unstiffened plate; (b) stiffened plate. 


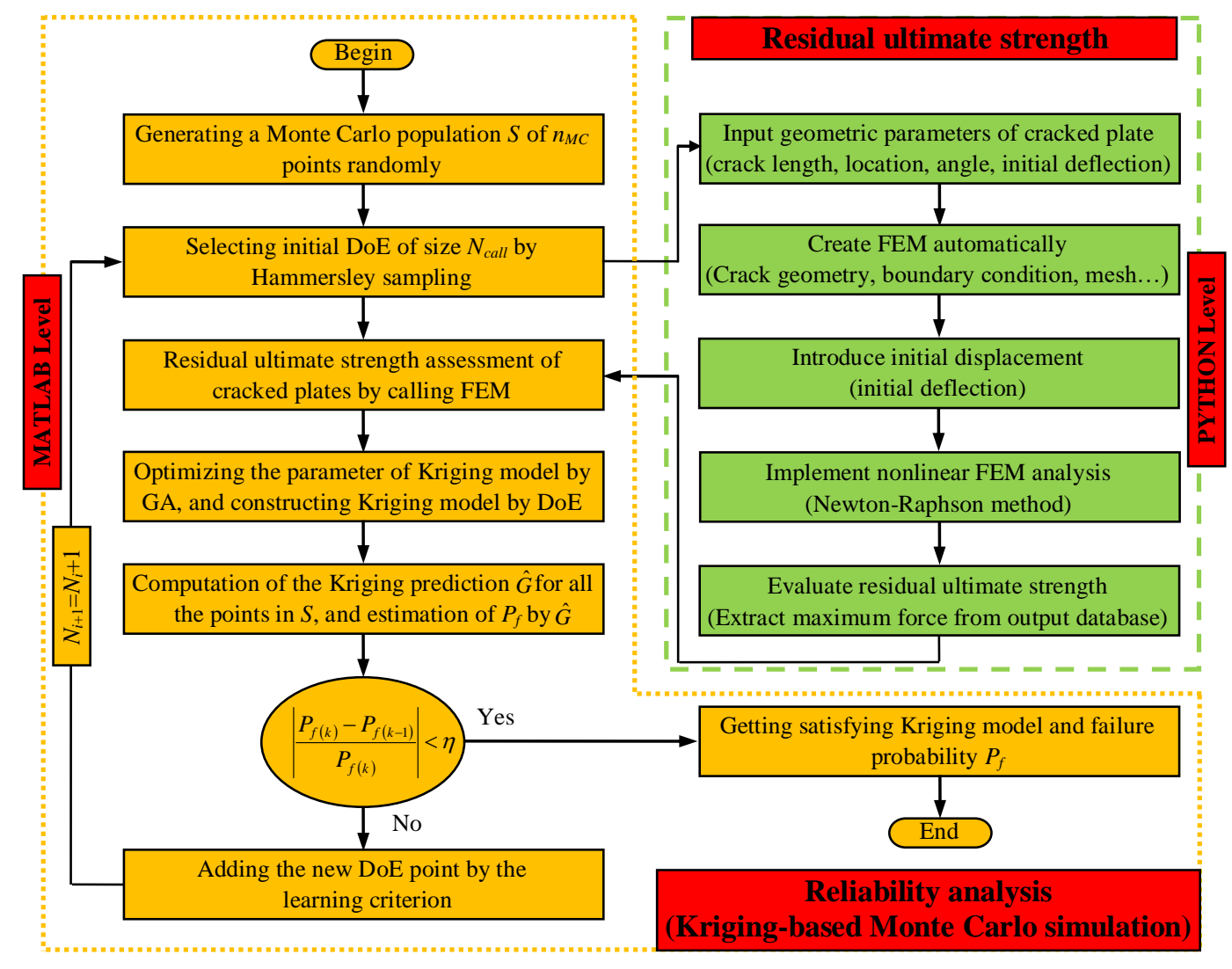

Fig. 5. Flowchart of the Kriging method for modeling probabilistic residual ultimate strength. 


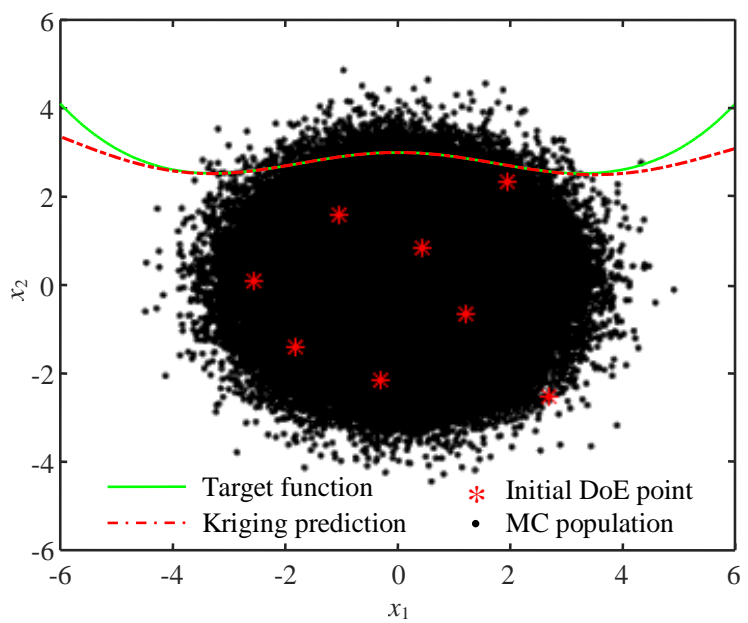

Fig. 6. Initial DoE points in an interesting localized subspace. 


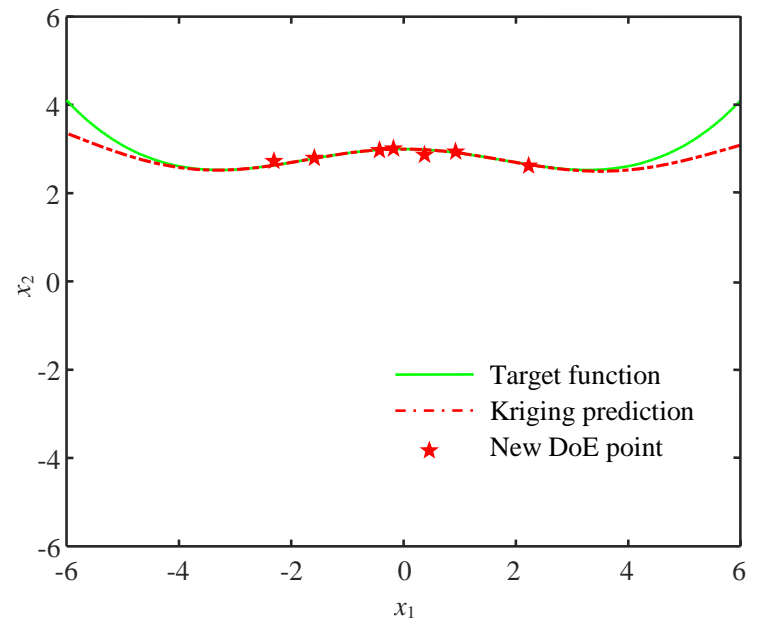

Fig. 7. Approximation by AK-MCS by adding new DoE point. 


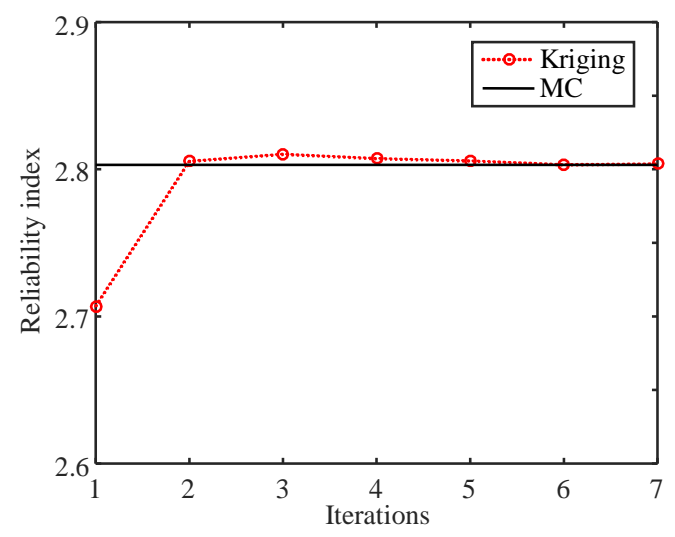

Fig. 8. Convergence histories for the Kriging result. 

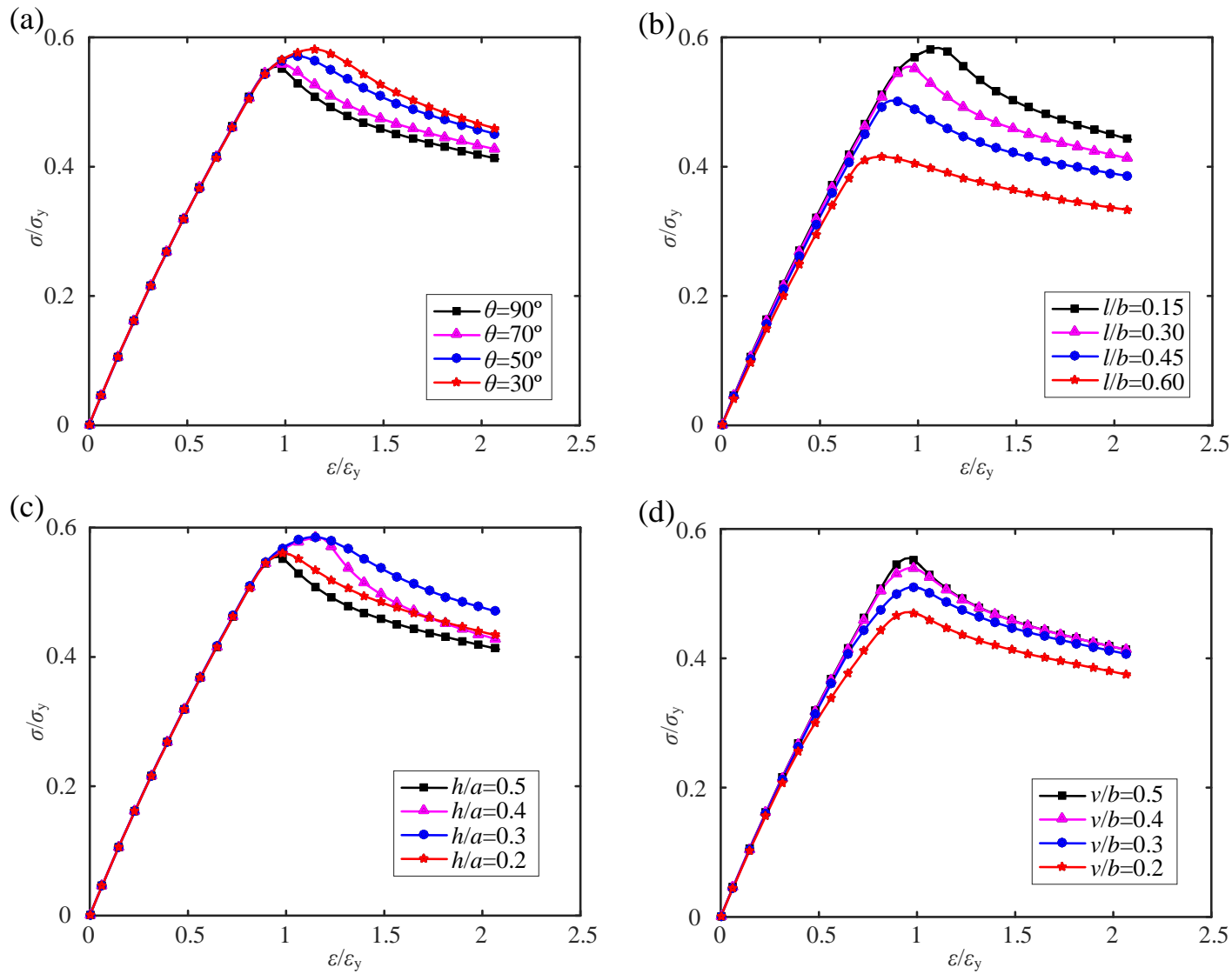

Fig. 9. Average stress-strain curves for different crack cases of unstiffened plates: (a) incline angle; (b) crack length; (c) longitudinal distance; (d) transverse distance. 


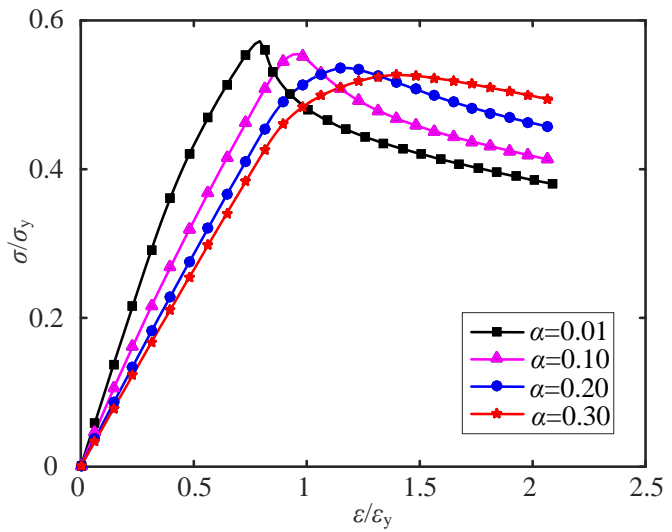

Fig. 10. Average stress-strain curves of cracked unstiffened plate with varying initial deflection amplitude coefficient $\alpha$. 

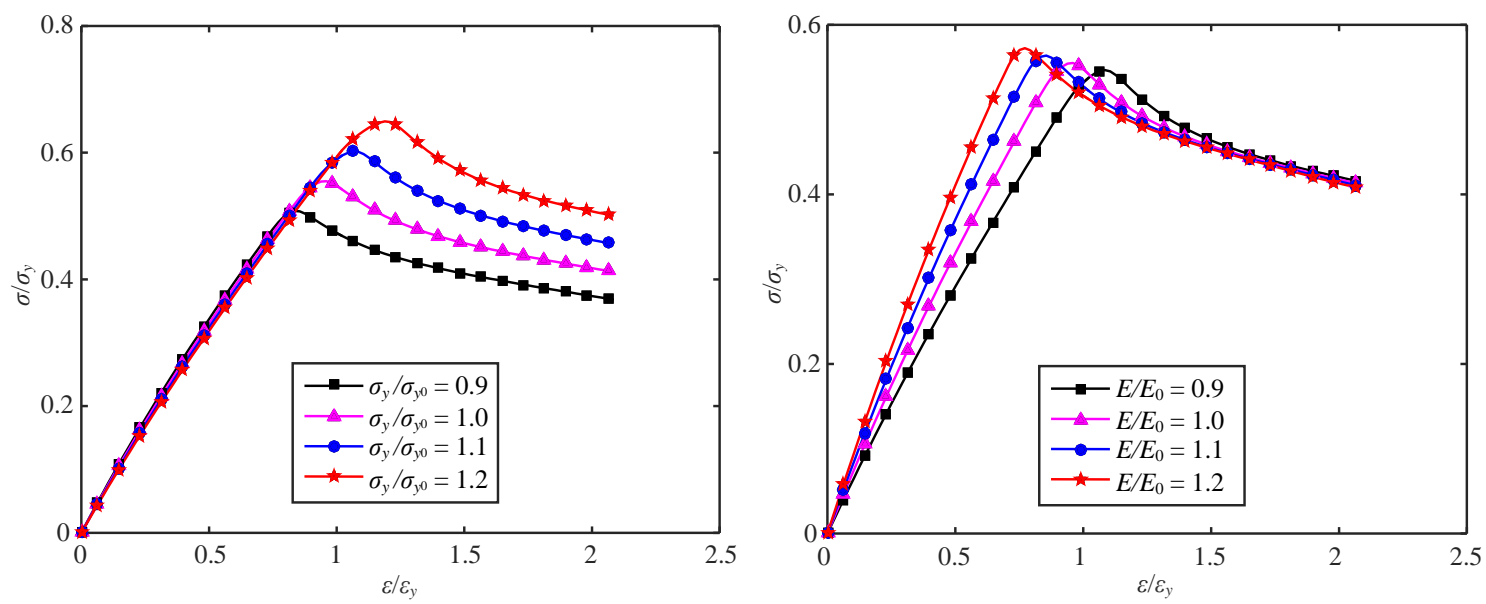

Fig. 11. Average stress-strain curves of cracked unstiffened plate with varying material parameters: (a) yielding stress; (b) elastic modulus. 

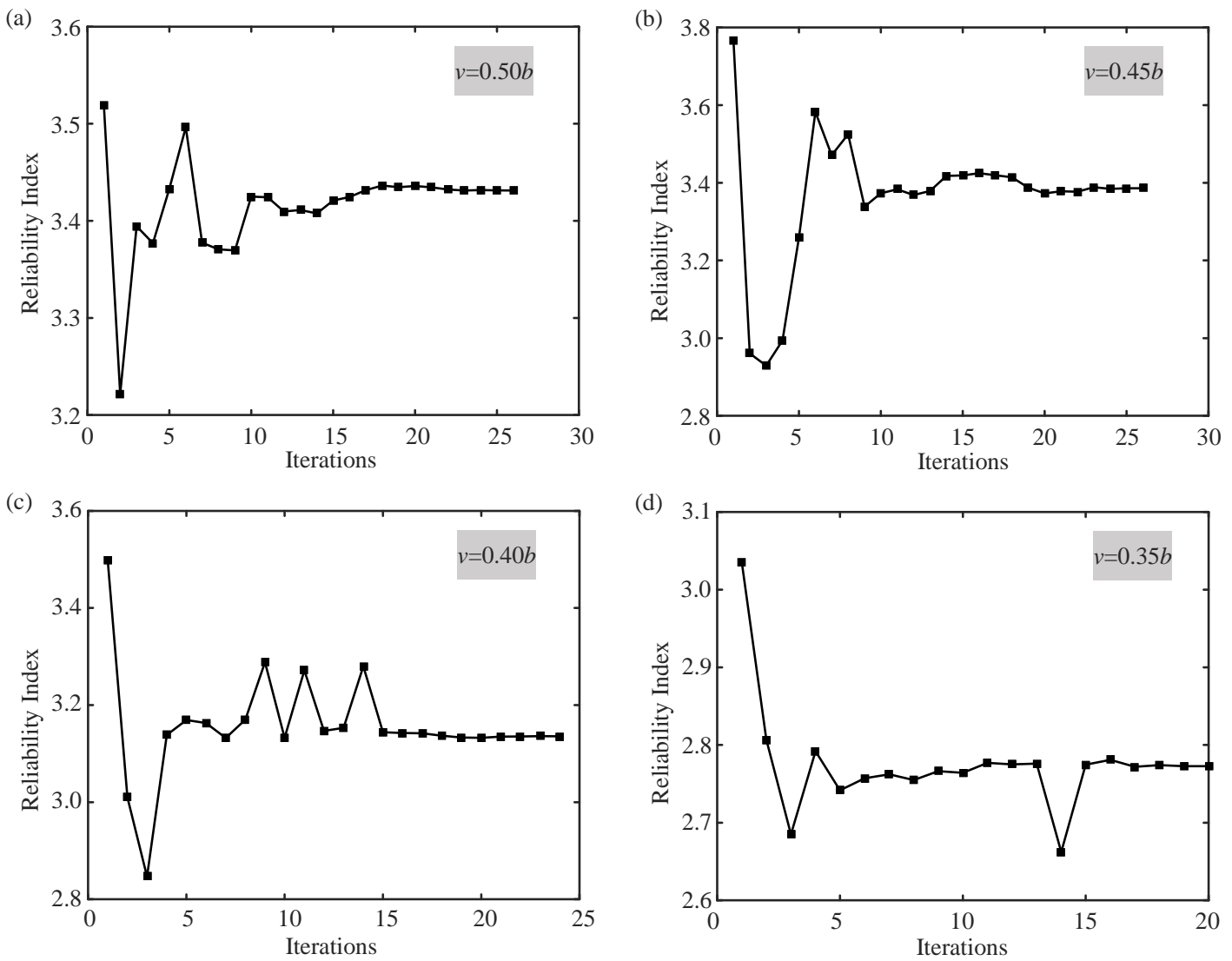

Fig. 12. Convergence histories of reliability indexes for cases with different transverse distances. 


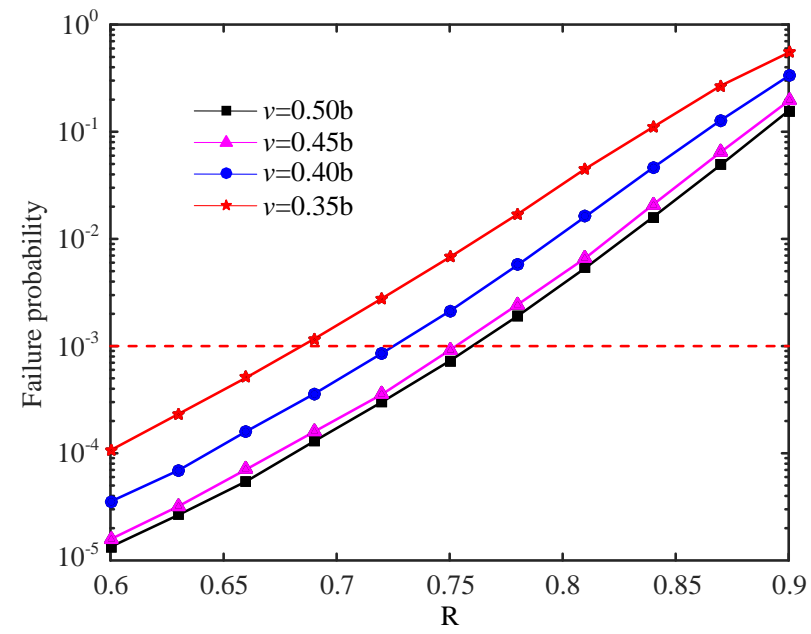

Fig. 13. Evolution of failure probability with different transverse distances. 


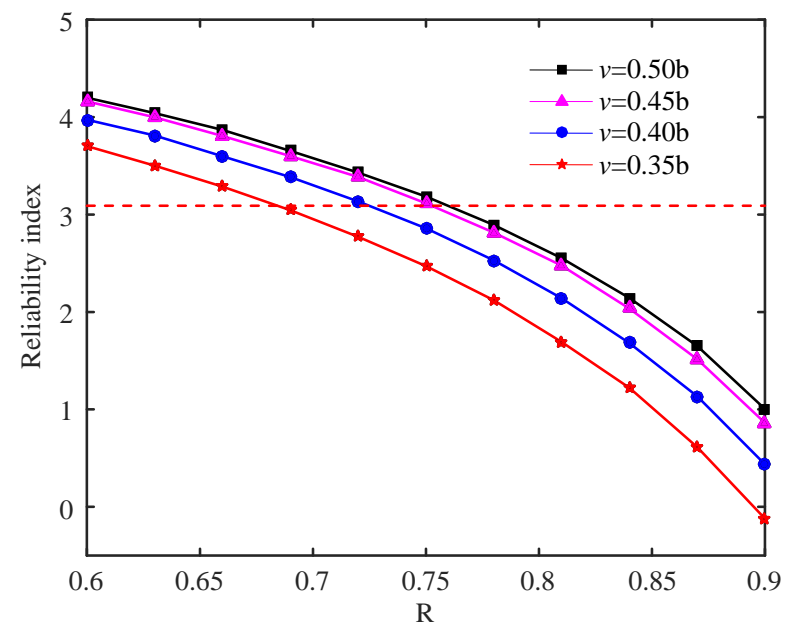

Fig. 14. Evolution of reliability index with different transverse distances. 


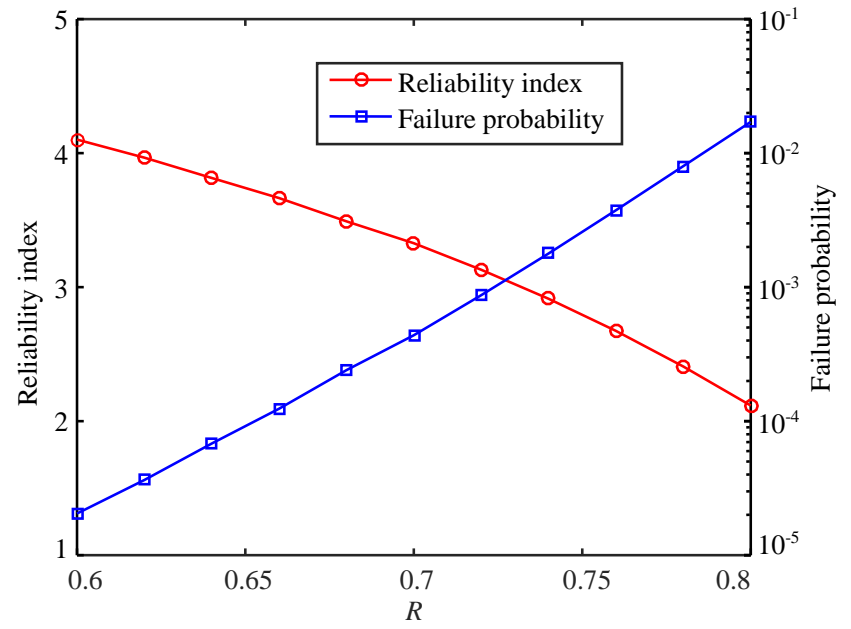

Fig. 15. Evolution of reliability index and failure probability of unstiffened plate. 

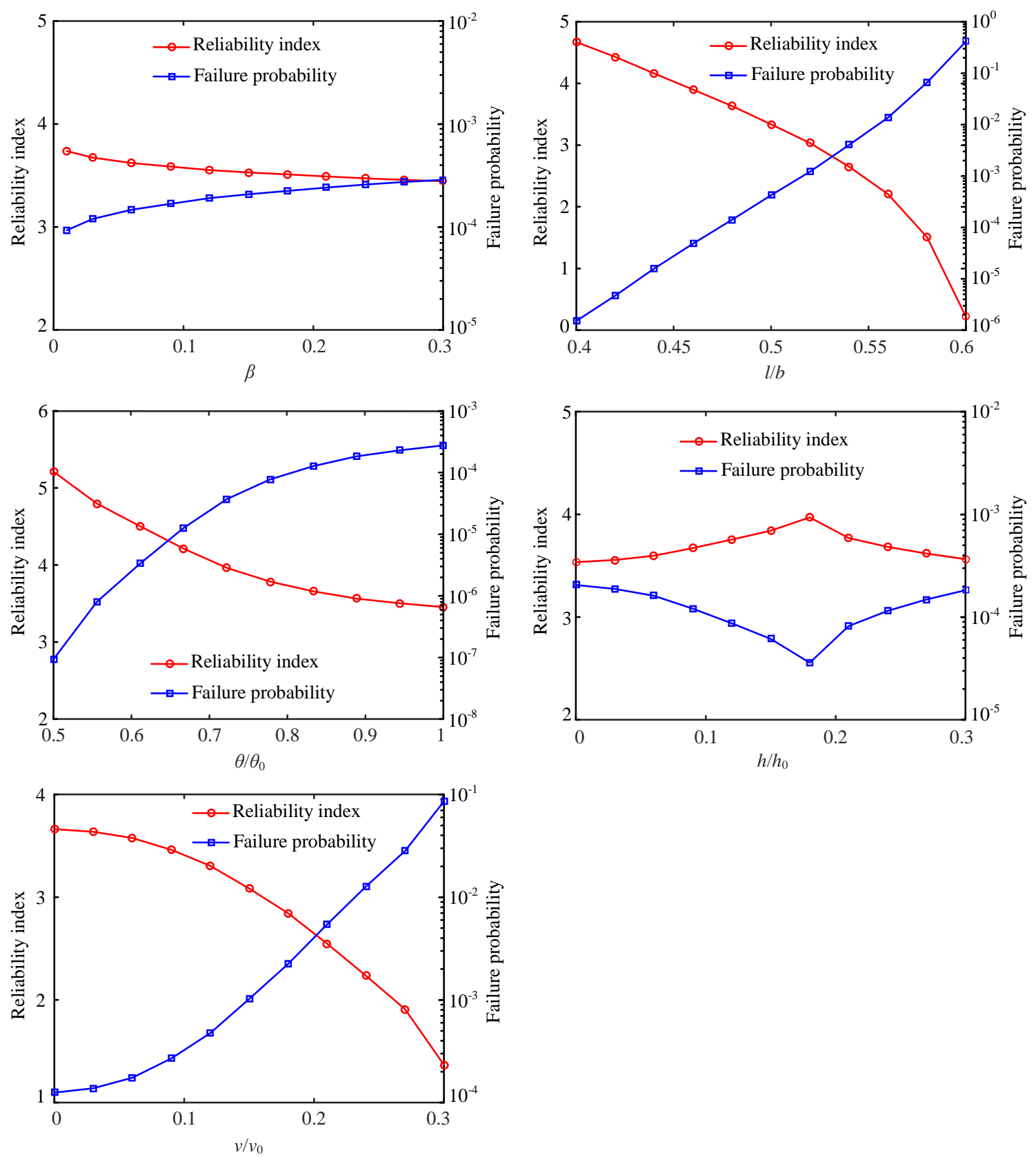

Fig. 16. Sensitivity analysis of each random variable on reliability index and failure probability of unstiffened plate. 


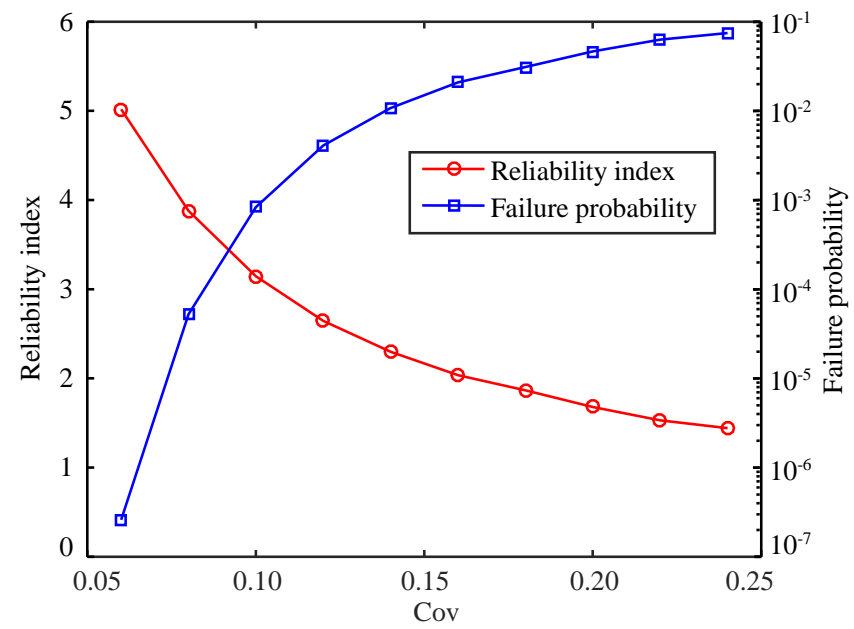

Fig. 17. Sensitivity analysis of COV on reliability index and failure probability of unstiffened plate. 

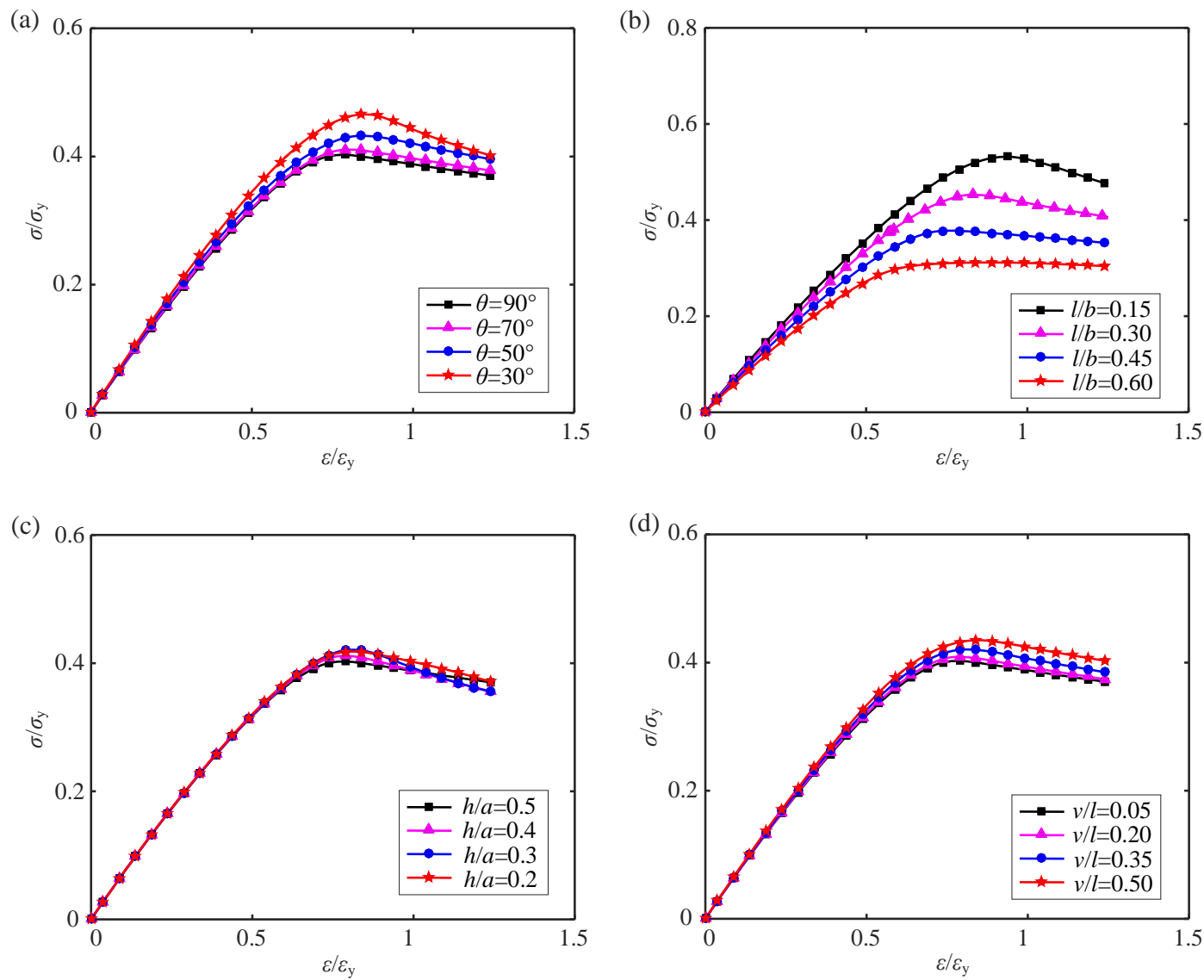

Fig. 18. Average stress-strain curves for different crack cases of stiffened plates: (a) incline angle; (b) crack length; (c) longitudinal distance; (d) transverse distance. 
(a)

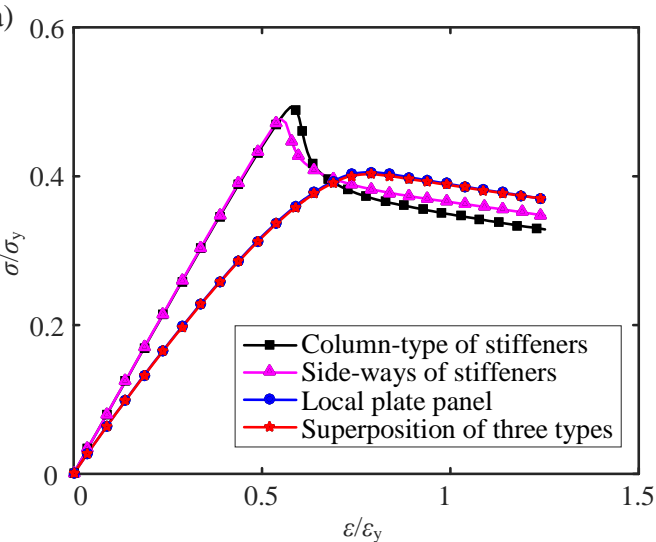

(b)

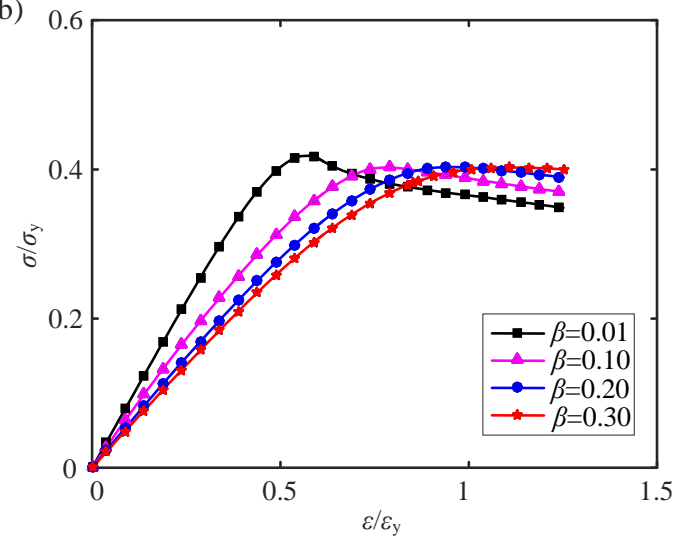

Fig. 19. Average stress-strain curves of cracked stiffened plate with different initial deflections. 

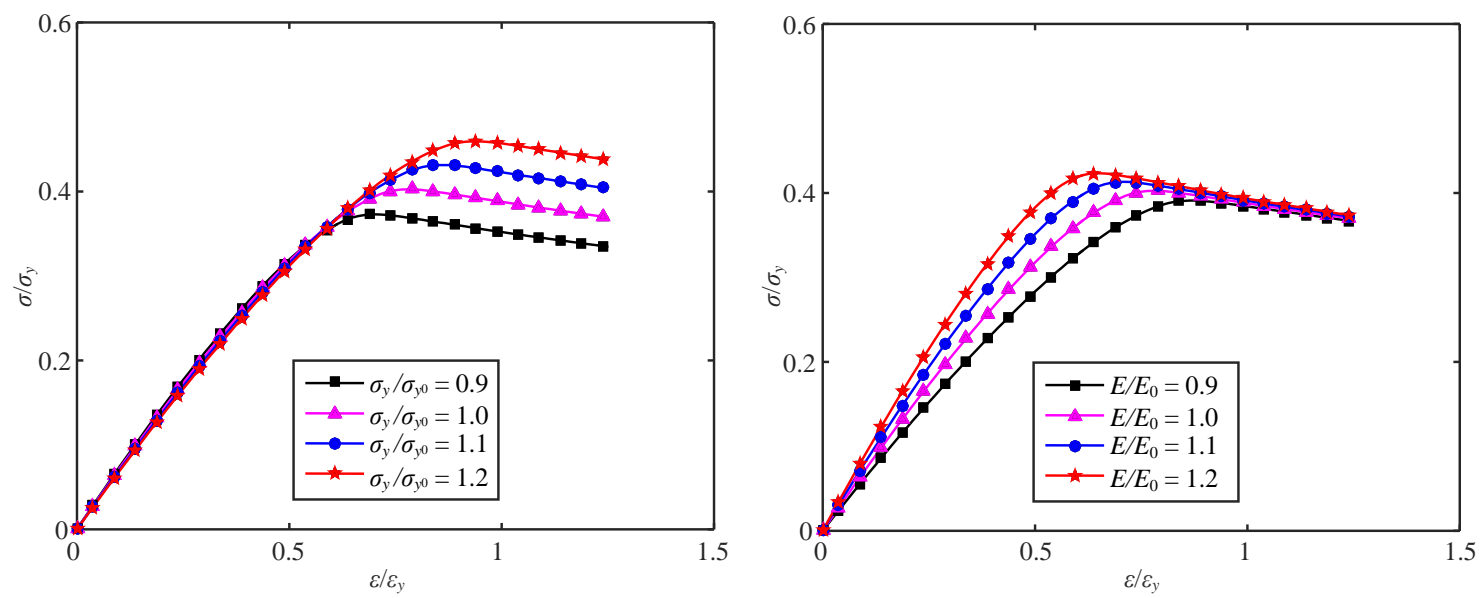

Fig. 20. Average stress-strain curves of cracked stiffened plate with varying material parameters: (a) yielding stress; (b) elastic modulus. 

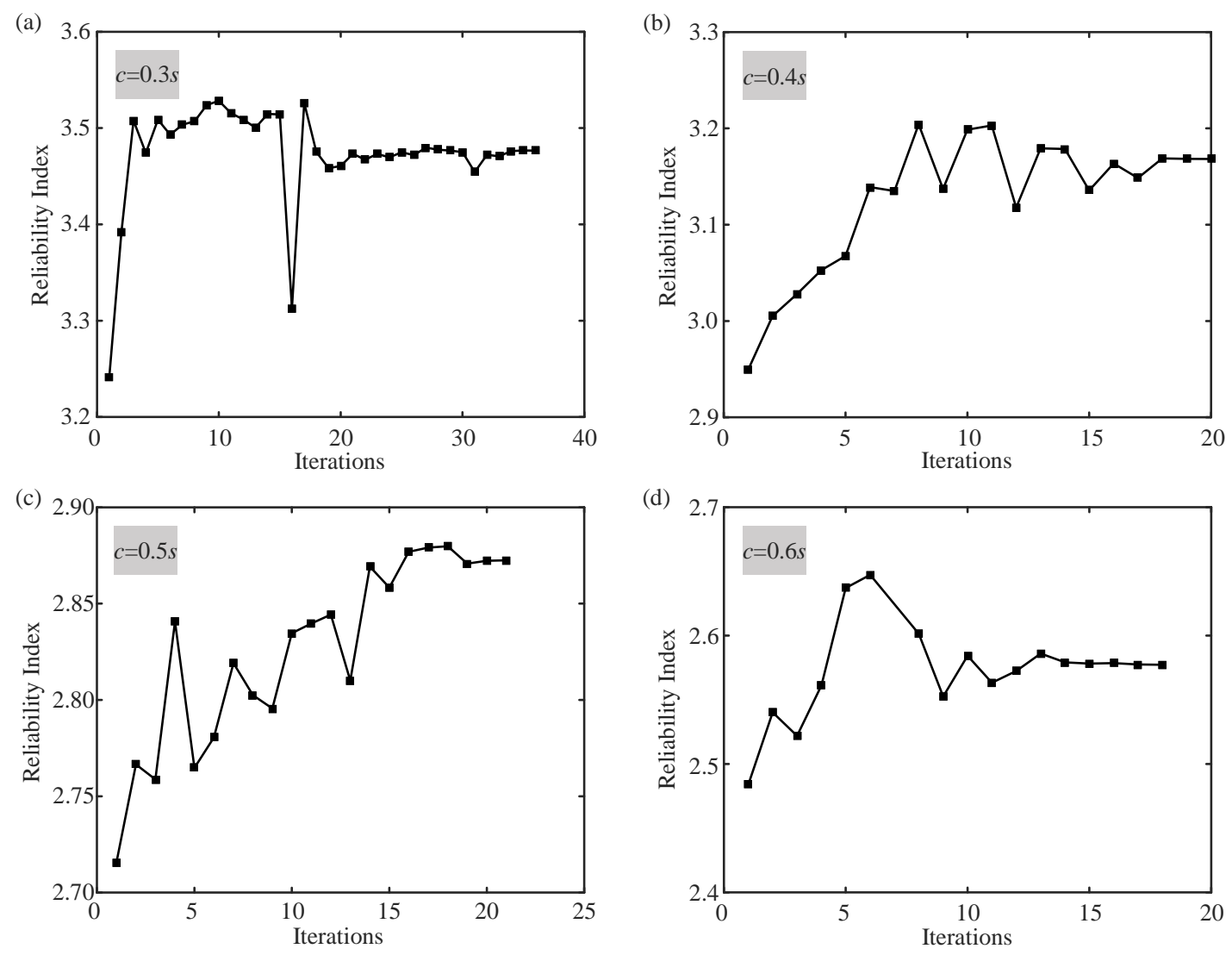

Fig. 21. Convergence histories of reliability indexes for cases with different crack lengths in stiffener. 


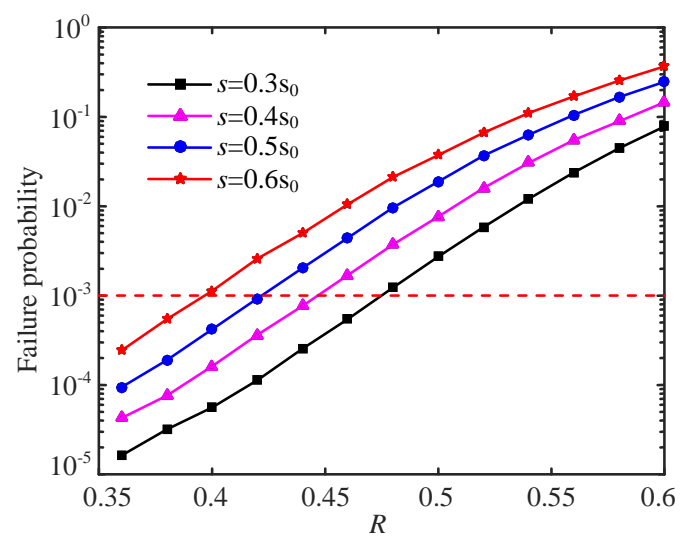

Fig. 22. Evolution of failure probability with different crack lengths in stiffener. 


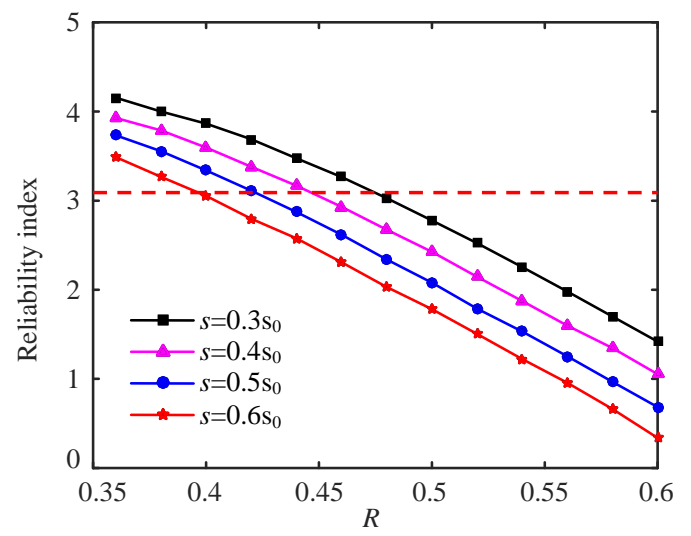

Fig. 23. Evolution of reliability index with different crack lengths in stiffener. 


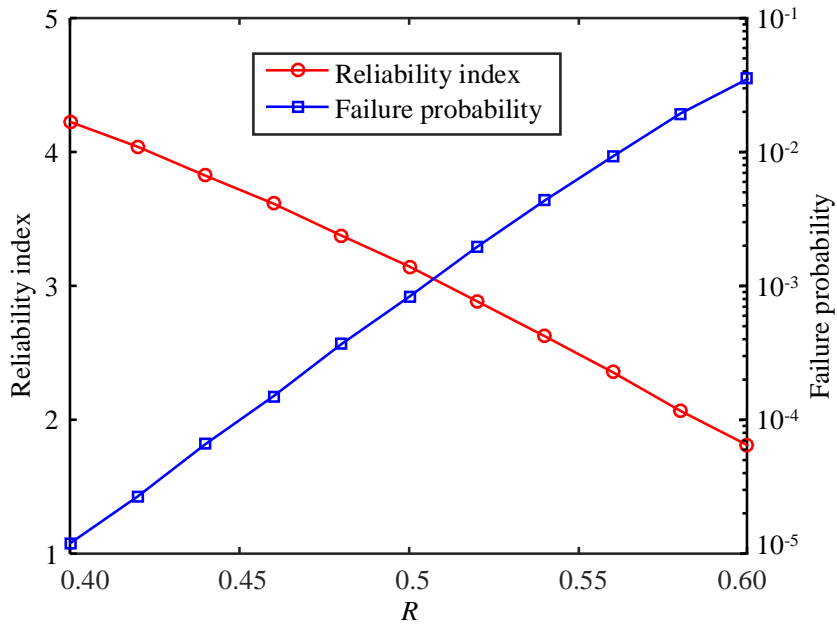

Fig. 24. Evolution of reliability index and failure probability of stiffened plate. 

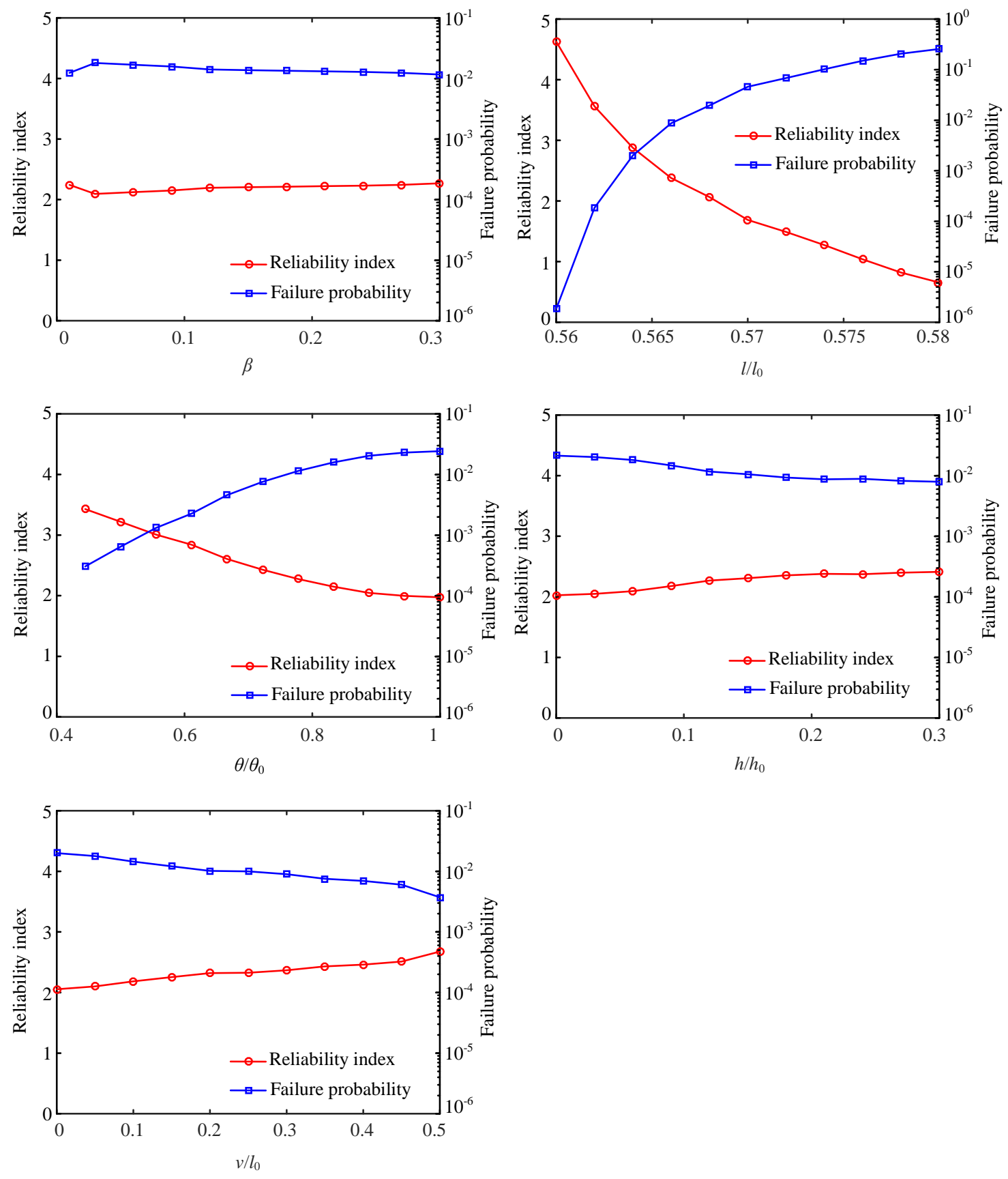

Fig. 25. Sensitivity analysis of each random variable on reliability index and failure probability of stiffened plate. 


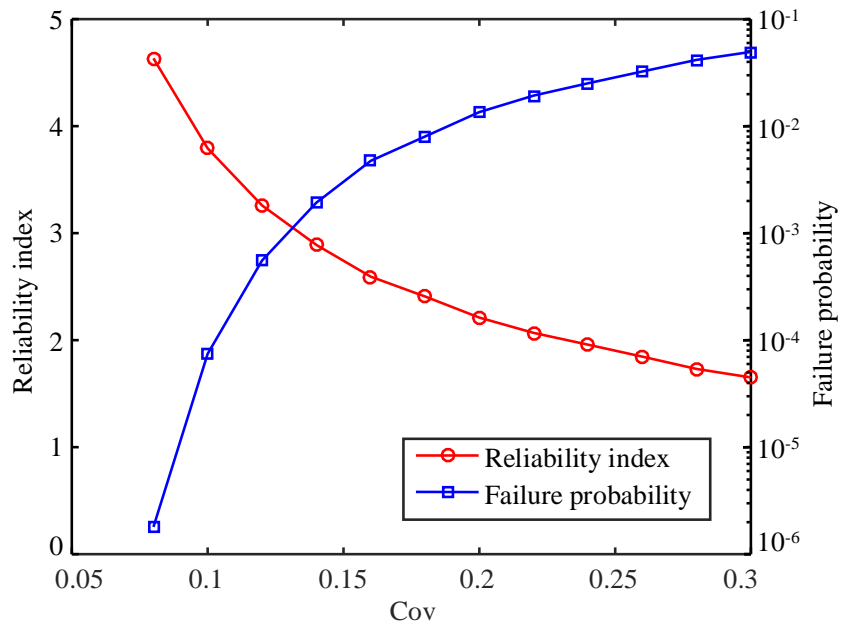

Fig. 26. Sensitivity analysis of Cov on reliability index and failure probability of stiffened plate. 


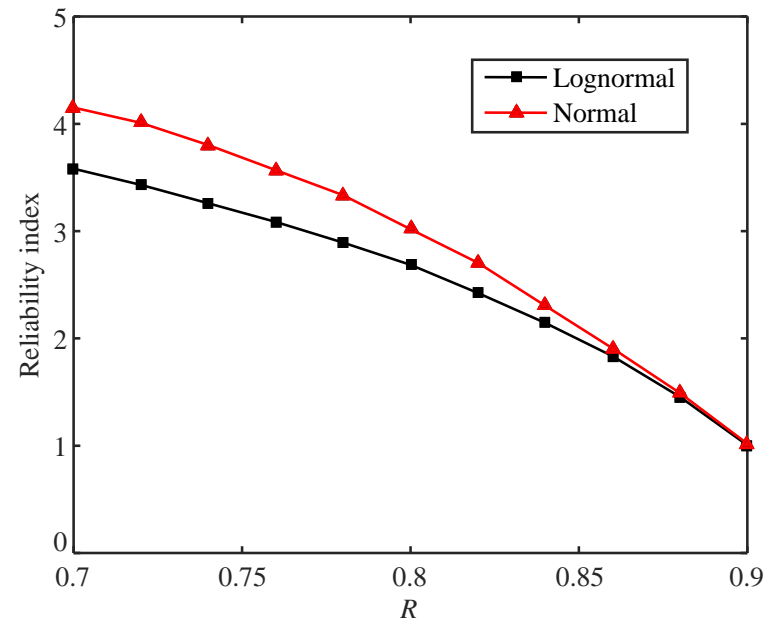

Fig. A1. Sensitivity analysis of distribution type on reliability index and failure probability of unstiffened plate. 